\title{
Submesoscale coherent vortices in the deep Brazil Basin
}

\author{
by \\ Patricia Kassis \\ B.S., Willamette University, 1996 \\ Submitted in partial fulfillment of the requirements for the degree of \\ Master of Science in Physical Oceanography

$$
\begin{gathered}
\text { at } \\
\begin{array}{c}
\text { Massachusetts Institute of Technology } \\
\text { and }
\end{array}
\end{gathered}
$$ \\ Woods Hole Oceanographic Institution \\ (C)2000 Patricia Kassis. All rights reserved. \\ The author hereby grants to MIT and to WHOI permission to reproduce and to distribute \\ copies of this thesis document in whole or in part.
}

August 2000

Signature of Author

Joint Program in Physical Oceanography Massachusetts Institute of Technology Woods Hole Oceanographic Institution

Certified by

Dr. W. Brechner Owens

Scientist

Woods Hole Oceanographic Institution

Thesis Advisor

Accepted by

Dr. W. Brechner Owens

Chairman, Joint Committee on Physical Oceanography Massachusetts Institute of Technology Woods Hole Oceanographic Institution 


\begin{abstract}
With Lagrangian and hydrographic data taken in the deep Brazil Basin, we identify several submesoscale coherent vortices (SCVs). These features contrast with SCV paradigms in that float data indicate approximately equal populations of cyclonic and anticyclonic vortices, and hydrographic data suggest that roughly half exhibit the convex lens shape generally associated with SCVs, while half are instead shaped like a concave lens, with isopycnal surfaces pinched together. There is some evidence that the vortex cores may be enriched in warm, salty North Atlantic Deep Water, suggesting formation in the north or northwest regions of the basin. Data is available from 153 floats which were ballasted for 2500 and 4000 $d b$ pressures. They tracked 34 eddies, which are believed to be roughly $30 \mathrm{~km}$ in diameter, and rotate with apparent periods of about 30 days. Many floats experienced formation or entrainment events, and destruction or detrainment events, near seamounts.
\end{abstract}




\section{Acknowledgments}

I am grateful to Breck Owens and Nelson Hogg for advising and supporting me. My thanks go also to the scientists who acquired hydrographic data in the Brazil Basin, especially Bill Smethie and Georges Weatherly, who kindly provided hydrographic data taken in a floattracked eddy. I benefited from an informal exchange of ideas with Weatherly and Claudia Schmid. This work was supported by the National Science Foundation, grants OCE 99-11148 and OCE 94-15509.

Thanks to my friends and classmates: especially Sarah Samuel for telling me exactly what to do, the crew of bridge payers (who'll remain nameless here for their own protection) for keeping me sane and distracted, Pablo Zurita, whose pioneering homework assignments continue to benefit all who succeed him, Lou St. Laurent for laughing at my jokes and not laughing at my tears, and Marc Kassis, my best friend. 


\section{Contents}

1 Introduction $\quad 11$

1.1 SCVs Defined . . . . . . . . . . . . . . . . . . . . . . . . . . . . . . . .

1.2 Observations of SCVs . . . . . . . . . . . . . . . . 12

1.3 Formation Mechanisms . . . . . . . . . . . . . . . . . . . . 13

1.4 Deep Basin Experiment . . . . . . . . . . . . . . . . 15

2 Lagrangian Studies $\quad 17$

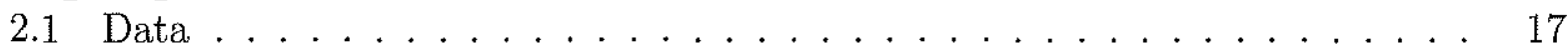

2.2 Fitting Technique . . . . . . . . . . . . . . . . 18

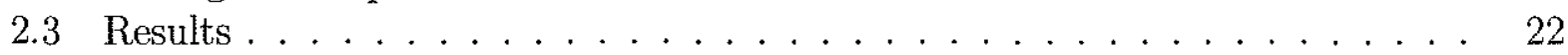

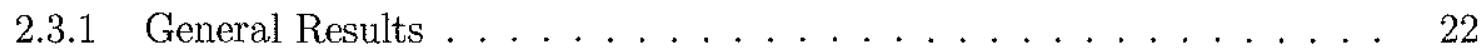

2.3 .2 Translational Velocities . . . . . . . . . . . . . . 26

2.3.3 Bathymetric Influence in Formation and Destruction . . . . . . . . 31

2.3.4 Temperature Trends in Float Data . . . . . . . . . . . . . . . . . 34

2.4 Float 188: An Eddy Observed by Float and Hydrography . . . . . . . . . . 38

2.4.1 Float Data . . . . . . . . . . . . . . . . . 38

2.4 .2 Hydrographic Section . . . . . . . . . . . . . . . . . . 40

2.5 Conclusions . . . . . . . . . . . . . . . . . . 43

3 A Search for Eddies in Hydrographic Data 45

3.1 Datasets . . . . . . . . . . . . . . . . . . . 45

3.1 .1 HydroBase Data . . . . . . . . . . . . . . . . . . . . . . . . . . . . . . . . . 46

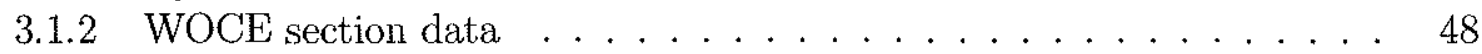

3.2 Eddy Identification Criteria . . . . . . . . . . . . . . . . . . . . 48

3.3 Results . . . . . . . . . . . . . . . . . . . . . . . . . . . . . . . . . . .

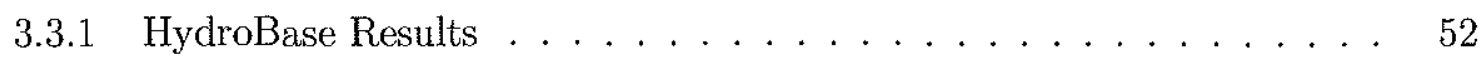

3.3 .2 WOCE Results . . . . . . . . . . . . . . . . 54

3.4 Conclusions . . . . . . . . . . . . . . . . . 63 


\section{List of Figures}

2.1 Deployment sites for all floats, and trajectories of looping floats superimposed on a map of the Brazil Basin . . . . . . . . . . . . . .

2.2 Vectors representing the total displacement divided by total time for each looping float . . . . . . . . . . . . . . .

2.3 Trajectories of anticyclones whose direction of propagation contrasts with ex-

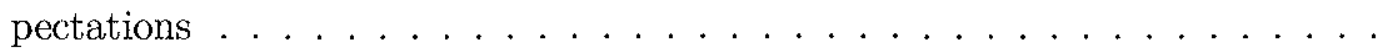

2.4 Trajectory of a float which began looping above a seamount $\ldots \ldots \ldots$

2.5 Trajectory of a float which began and ended looping above a seamount . . .

2.6 Temperature records for several floats $\ldots \ldots \ldots \ldots \ldots$

2.7 Float 188: trajectory, temperature record and pressure record $\ldots \ldots . \ldots 39$

2.8 Float 188: hydrographic data taken when the float was deployed . . . . . . . 41

3.1 Geographic distribution of HydroBase stations . . . . . . . . . . . . . 47

3.2 Geographic distribution of WOCE hydrographic stations . . . . . . . . . 49

3.3 Geographic distribution of HydroBase stations identified as convex or concave

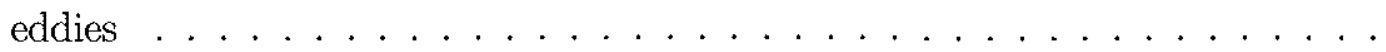

3.4 Histograms of temperature and salinity anomalies of eddies identified in $\mathrm{Hy}$ droBase data . . . . . . . . . . . . . . . 55 
3.5 Map of salinity at the $\sigma_{2}=36.9$ density level in the Brazil Basin . . . . . 56

3.6 Map of temperature at the $\sigma_{2}=36.9$ density level in the Brazil Basin . . . 57

3.7 Geographic distribution of WOCE stations identified as convex or concave

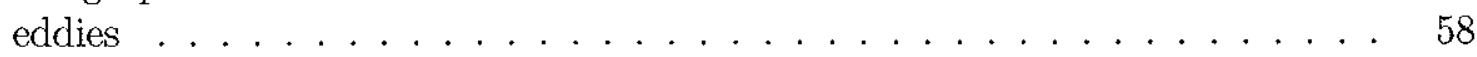

3.8 Histograms of temperature and salinity anomalies of eddies identified in WOCE hydrographic data . . . . . . . . . . . . . . 59

3.9 Examples of eddies identified in WOCE hydrographic data . . . . . . 61

3.10 Distribution of cyclonic and anticyclonic eddies with depth, as determined from each of the three datasets used . . . . . . . . . . . . . 62 


\section{List of Tables}

2.1 Characteristics of the eddies tracked by floats 153,188 and 209, each of which experienced an abrupt change in frequency . . . . . . . . . . .

2.2 The depths, rotation frequencies, record lengths, radius estimates, mean speeds, swirl speeds, and directions of propagation of the 34 tracked eddies . . . . 


\section{Chapter 1}

\section{Introduction}

This study examines features called submesoscale coherent vortices (SCVs) found in the deep Brazil Basin, the site for WOCE's Deep Basin Experiment (DBE). The following provides an introduction to SCVs and to the Brazil Basin.

\subsection{SCVs Defined}

Within the last 30 years, hydrographic, Lagrangian and moored data have revealed and verified the existence of small, baroclinic eddies in the ocean basins. McWilliams summarized the defining characteristics of these SCVs in a 1985 review paper. They are vertically more isolated than mesoscale eddies, horizontally not larger than the baroclinic deformation radius (ie. with Burger numbers near or below unity), and exhibit velocities which are circular, horizontal and axisymmetric. McWilliams observes that SCVs are nearly always characterized by a vertical bowing out of isopycnals, a shape associated with anticyclonic circulation. Water in the center of an SCV is trapped and transported within the eddy. Because SCVs 
are long lived and capable of moving great distances in a lifetime, they can play an important role in isopycnal mixing. Mediterranean eddies (meddies) are an example of SCVs.

\subsection{Observations of SCVs}

McWilliams (1985) notes fully 13 types of SCVs, including the well observed meddies and Arctic SCVs, several varieties identified during the Local Dynamics Experiment (located in the western North Atlantic), and a singly observed South Atlantic abyssal SCV whose water properties are not anomalous compared to nearby waters. McWilliams notes that while a few outliers in hydrographic data may suggest property anomalies centered at a maximum in stratification (an SCV with isopycnals pinched together instead of bowed out), no such cyclonic SCV "has yet been observed with sufficient completeness that its identification as such is indisputable." This break in parity is attributed to what McWilliams claims is the dominant SCV formation mechanism: mixing and geostrophic adjustment.

Within a few years, additional observations of cyclonic SCVs were published. Schauer (1989), Colin de Verdiere et al. (1989) and Paillet et al. (1998) report hydrographic and current meter observations from the Eastern North Atlantic of concave, cyclonic (but otherwise meddy-like) SCVs. These features are found primarily in a region north of the area where anticyclonic meddies have been observed. While meddies can be described as a particularly thick layer of Mediterranean Water, these cyclones are instead a particularly thin layer of Labrador Sea Water. Mediterranean Water from above and North Eastern Atlantic Deep Water from below fill the hole, and the result is a pinch in isopycnals (Colin de Verdiere et al. 1989). This geometry is confirmed by hydrographic data, and the cyclonic rotation is 
confirmed by current meter measurements. Paillet et al. (1998) recognize that mixing and adjustment are not likely to create these cyclones. Noting that they found cyclones north of the Labrador Sea Water - Deep Mediterranean Water front, and anticyclones south of it, they suggest that formation is instead due to frontal instabilities.

Rossby numbers typical of anticyclonic SCVs (calculated here as the ratio of relative vorticity to planetary vorticity) range from 0.16 (McWilliams, 1985) to 0.54 (Richardson et al. , 1989). Colin de Verdiere (1989) reports similar numbers for the observed cyclones. These Rossby numbers are high enough to invalidate the apparently common (Beckman \& Kase, 1989; Meacham et al. , 1994; Walsh, 1992; Walsh, 1995) practice of studying SCVs using quasi-geostrophy.

\subsection{Formation Mechanisms}

There are several candidates for how SCVs originate. McWilliams advocates a mechanism capable of explaining the observed anticyclonic bias. Bearing in mind our anomalous observations, the following section will introduce formation mechanisms.

The formation mechanism advocated by McWilliams (1985) consists of diapycnal mixing events followed by geostrophic adjustment. This scenario describes the formation of meddies, where it is imagined that instabilities of the Mediterranean outflow can produce a parcel of well mixed water which sinks to a level consistent with its density. The result is a bowing out, in the vertical, of isopycnal surfaces, and geostrophic adjustment then causes anticyclonic rotation. Aside from an inflow of water, McWilliams suggests that the diapycnal mixing event could be caused by Kelvin Helmholtz instabilities, chimneys (only 
known to occur in a few isolated locations), or coupling to a frictional layer (unlikely in the abyss, where wind does not apply and bottom friction is probably too weak). McWilliams dismisses these other formation mechanisms: flow around topography, instabilities in jets, and 2-dimensional vorticity concentration. The fatal flaw for all three is that, over a global average, they would not create the observed worldwide bias toward anticyclonic rotation of SCVs. A rigorous discussion of these mechanisms is beyond the scope of this paper, but the following paragraphs touch on conceptual models for understanding two of the mechanisms.

While it is unclear that flow over bathymetry would necessarily produce equal numbers of cyclones and anticyclones, one can envision several scenarios in which vortices of either sign are produced. For example, an unsteady flow could move a column of water away from its initial location above a seamount, resulting in stretching and, therefore, cyclonic rotation. A column being displaced up such a slope would rotate anticyclonically. Jets passing alongside a seamount may experience increased frictional drag, causing horizontal sheer leading to instabilities, or flow over a seamount may cause pairs of vortices to form, as is often observed in cloud patterns downwind from islands.

Baroclinic instability, in its simplest form, occurs in two vertically stacked layers which are in thermal wind balance and moving in different directions or at different speeds. This corresponds to a sloping of their mutual interface. If a column of water from one layer moves to a place where that layer is, say, shallower, it will both change its relative vorticity and, by impinging on the layer beneath, compress another column which will therefore also experience a change in relative vorticity. If, at the same time, another perturbation in the other layer acts similarly, and if the perturbations are arranged geometrically in a certain way, the two perturbations can extract energy from the mean flow and grow (Cushman- 
Roisin, 1994). If the geometry is indeed such that the disturbance grows, several pairs of adjacent eddies of opposite rotational sense are created. Initially, at least, each eddy of the pair will travel under the influence of the other (and of nearby pairs), causing the pair to continue to travel in the direction in which it was initially displaced. Thus, we see another possible formation mechanism for horizontal pairs of SCVs.

\subsection{Deep Basin Experiment}

As part of WOCE (the World Ocean Circulation Experiment), the DBE is an effort to investigate the dynamics of deep circulation in the world ocean, and to examine the Brazil Basin. This basin was chosen because the bottom topography is fairly flat, the in- and outflows are especially easy to monitor, and previous measurements have suggested that the Brazil Basin has a low mesoscale eddy energy (Hogg et al. , 1996).

The Brazil Basin is the northwestern quadrant of the South Atlantic, and is bounded by the South American continental shelf on the west, the mid-Atlantic ridge on the east and north, and on the south by the Rio Grande Rise, which is cut by two channels: the deeper Vema Channel to the west and the shallower Hunter Channel to the east. The Basin's primary water masses are Antarctic Intermediate Water (AAIW) (above about 1400 meters depth), North Atlantic Deep Water (NADW) (1400 to 3500 meters depth), and Antarctic Bottom Water (AABW) (below 3500 meters depth) (De Madron and Weatherly, 1994). Among the goals of this project are the examination of circulation and of mixing processes in the basin (Hogg et al. , 1996).

Antarctic Bottom Water enters the basin through the Vema and Hunter Channels and, 
while in the Brazil Basin, mixes extensively both laterally and diapycnally with NADW (De Madron and Weatherly, 1994). About 4 Sverdrups of water colder than $1^{\circ} \mathrm{C}$ enter the basin, but all water leaving the basin is observed warmer than $1^{\circ} \mathrm{C}$. If the basin's temperature is indeed in steady state, the implication is that a great deal of mixing occurs. One of the goals of the DBE is to examine where and by what mechanism this mixing happens (Hogg et al. , 1996).

Eddies are a vehicle for mixing along isopycnals, because generally they move faster than water around them. Garrett (1989) argues that eddies can also result in net diapycnal transfer in the presence of diabatic processes such as internal waves. Thus, eddies may contribute significantly to transfer across mean isopycnal surfaces.

As part of an effort to study circulation in the deep Brazil Basin, several isobaric RAFOS floats were deployed throughout the basin. The floats had target pressures of either 2500 or $4000 d b$ (one set designed to track NADW, the other to track AABW), and were programmed to surface after 800 days of collecting pressure, temperature, and position data. This study focuses on the subset of floats which tracked SCVs. 


\section{Chapter 2}

\section{Lagrangian Studies}

\subsection{Data}

As part of the DBE, 168 isobaric RAFOS floats were deployed, 99 with target depths of $2500 \mathrm{db}$, and 69 with target depths of $4000 \mathrm{db}$. They were programmed to resurface after 800 days. In total, 153 floats resurfaced and provided at least some information.

RAFOS floats are similar to their predecessors, SOFAR floats, whose position is determined by moored stations where sound signals produced by the floats are received. By reversing the system (using moored sound sources and equipping the floats with listening and recording devices), the ease of launching was improved, the data retrieval (now possible exclusively by satellite instead of by ship) was made less expensive, and smaller studies became more cost effective. The float's instruments, aside from external sensors and ballast, are contained within a glass tube $1.5 \mathrm{~m}$ tall and $9 \mathrm{~cm}$ in diameter. After deployment, the float sinks to a prescribed pressure level where it tracks water parcels. Once a prescribed time period has elapsed, the float drops its ballast, surfaces, and transmits location, temperature 
and pressure records via satellite. For further information regarding RAFOS floats, see Rossby et al. 1986.

These floats were programmed to record data every 48 hours. After interpolating to fill in any gaps, the ensemble produced a total of 106,668 float days of data. Of these, 41,546 days were imperfect, with location produced by linear interpolation. Some of these gaps are long and do not provide us with information regarding whether or not the float was trapped in an eddy (one float has only 2 known points, the deployment site and the site where the float resurfaced), but many involve only a single point, which would not mask the presence of an eddy. The result is about 87,000 days of usable data.

Ten floats recorded dramatic changes in pressure, due to a flooded drop weight. In only two cases was the float looping in an eddy either immediately before or after the sinking event. Floats 188 and 209 will be discussed in detail later, but both dropped more than 1000 $m$, and were trapped in an eddy both before and after the sudden change in depth.

A more detailed discussion of the floats and their failure trends, as well as an overview of the DBE, and preliminary analyses of float data, are available in Hogg and Owens (1999).

\subsection{Fitting Technique}

Deployment sites for all the floats, along with the visually identified looping trajectories, are shown in figure 2.1 .

A float was determined to be in an eddy if at least three adjacent loops occurred in the record of the float's position. An eddy whose translational velocity is large compared to its swirl speed may exhibit a trajectory free of visible loops, but this is not typically true 


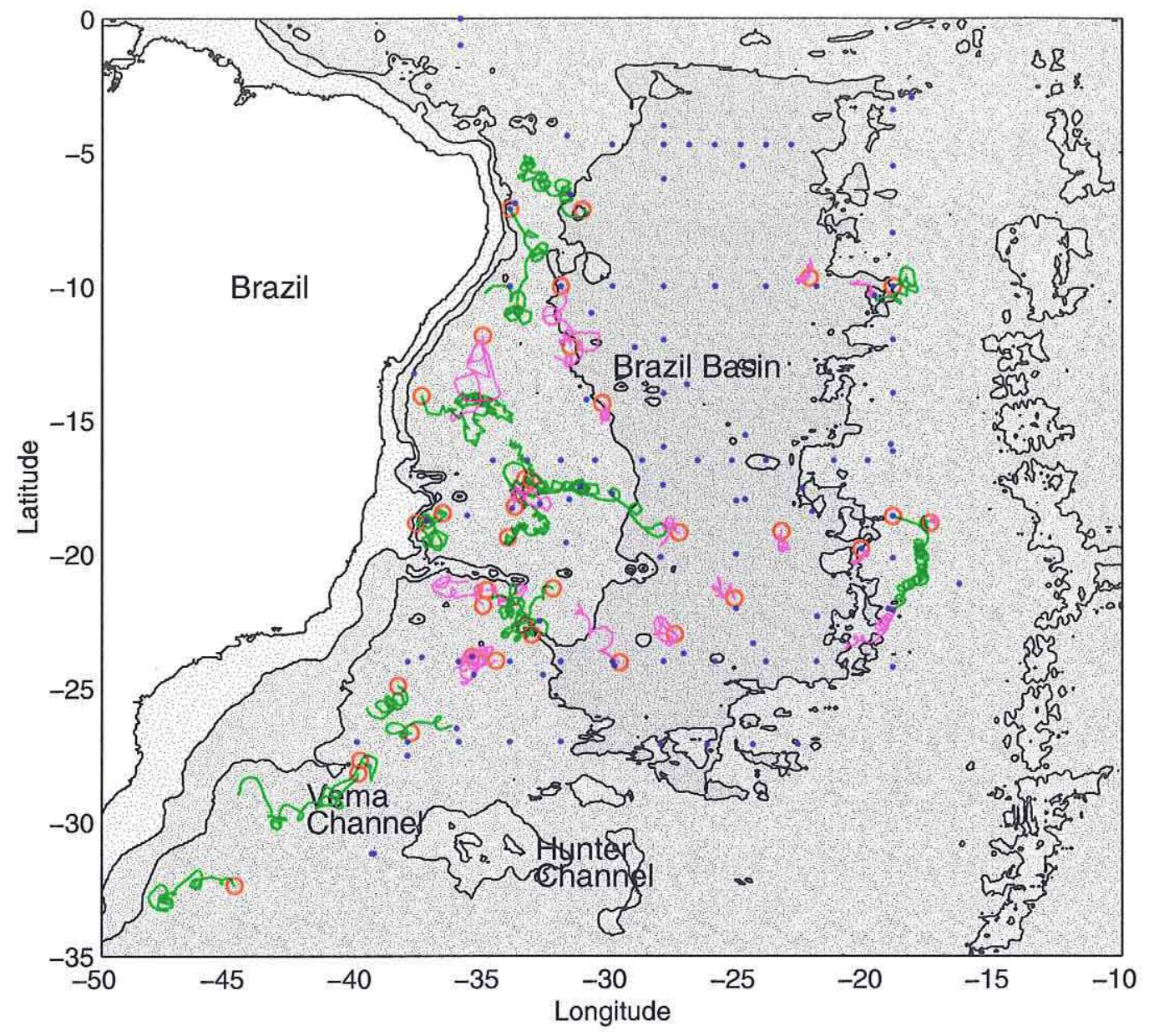

Figure 2.1: Deployment sites for all floats, as well as trajectories of looping floats, are shown. Green tracks indicate eddies shallower than $3000 \mathrm{~m}$, and magenta tracks indicate deeper eddies. Red circles mark where looping began. Isobaths at 0, 1000, 3000 and $5000 \mathrm{~m}$ are shown.

of SCVs. If the translational speed were indeed large, one would observe a scalloped path, composed (roughly) of consecutive half-ovals. No continuous tracks exhibited this pattern, although occasionally one such shape was found sandwiched between loops. Such trajectories were identified as SCVs.

Once an eddy was identified in the data, a fit was made to the trajectory to quantify parameters such as the frequency of rotation, the translational velocity, and the distance between the float and the eddy center. 
The float trajectories were fit to the model (Riser et. al., 1986):

$$
\begin{aligned}
& x=x_{o}+u_{o} t+R \cos (\omega t+\phi) \\
& y=y_{o}+v_{o} t+R \sin (\omega t+\phi)
\end{aligned}
$$

where $x$ and $y$ are displacements (east and north respectively) of the float, $x_{o}$ and $y_{o}$ are the location of the center of the eddy at the beginning of the fitting interval, $u_{o}$ and $v_{o}$ are the zonal and meridional translational velocities of the eddy center, $t$ is time, $R$ is the distance between the center of the eddy and the float, $\omega$ is the frequency of rotation, and $\phi$ is the phase.

Within each fitting interval, the radius, velocities and phase were assumed constant, and determined through a least squares fitting procedure, ultimately resulting in a time series, over all fitting intervals, of $u, v, R$ and $\phi$. The frequency $\omega$ is assigned and held constant throughout the time interval over which the eddy was tracked, and the resulting $\phi$ time series exhibits a sloping trend only if the choice of $\omega$ differs from the actual eddy frequency (see Riser et. al., 1986).

The fitting interval was chosen to be either five-, seven-, 15-, or 25-points (recall data points are separated temporally by 48 hours), based on a visual estimate of the eddy's period of rotation. The fitting intervals overlapped over roughly a third of their length.

The frequency $\omega$, which was assigned and held constant for each eddy, was determined based upon two factors: the residuals (sum of the distances squared between the data points and the fit generated points), and the mean slope of the time series $\phi$. A linear combination 


\begin{tabular}{|c||c|c|c|c|c|c|}
\hline \multicolumn{1}{|c||}{ Float } & \multicolumn{3}{c|}{ Regime 1 } & \multicolumn{3}{c|}{ Regime 2 } \\
\cline { 2 - 7 } & Frequency & Pressure & Duration & Frequency & Depth & Duration \\
\hline 153 & -.145 days $^{-1}$ & $2470 \mathrm{db}$ & 142 days & -.248 days $^{-1}$ & $2480 \mathrm{db}$ & 110 days \\
\hline 188 & .057 days $^{-1}$ & $2310 \mathrm{db}$ & 326 days & .034 days $^{-1}$ & $3460 \mathrm{db}$ & 324 days \\
\hline 209 & -.018 days $^{-1}$ & $2399 \mathrm{db}$ & 390 days & -.107 days $^{-1}$ & $3425 \mathrm{db}$ & 100 days \\
\hline
\end{tabular}

Table 2.1: The eddies tracked by floats 153, 188 and 209 exhibited abrupt and long-lived changes in frequency. Note that for floats 188 and 209, this change coincided temporally with an increase in depth, which was assumed caused by a flooded drop weight. Positive frequencies indicate cyclonic rotation, negative denote anticyclonic.

of these factors was minimized to determine the best fitting frequency $\omega$. With the $\phi$ time series record, however, a time series of the true frequency can always be calculated (see Riser et. al., 1986). For all but three eddies, this method of fitting each looping time series with one frequency proved reasonable, and resulted in an acceptable trajectory fit and $\phi$ time series. For three eddies, however, tracked by floats 188, 153, and 209, it became clear that an abrupt change in frequency occurred. In the cases of floats 188 and 209 , this frequency change corresponded temporally with a float malfunction; the drop weight flooded, causing the float to sink more than $1000 \mathrm{~m}$ in both cases. No other float experienced a flooded drop weight while in an eddy. It remains unclear why the eddy tracked by float 153 experienced a similar frequency change, but the change was abrupt and both frequency regimes remained for at least 100 days. These float trajectories were all fitted with 2 separate $\omega$ values (see table 2.1). In the general results presented below, where mean and median values of fit parameters (and characteristic derived from fit parameters) are discussed, the mean frequencies (and depths) are used for these floats.

In addition, six floats experienced two or more looping events separated temporally by long periods without looping. Accordingly, two separate segments in the trajectories of floats $38,84,178$, and 197 are each treated as individual eddies, as are three separate 
segments in the trajectory of float 291. After sinking, float 209 also stopped looping and began looping again in what is assumed to be a different eddy, and is accordingly fit with a different frequency value.

One additional eddy, tracked by float 195, exhibited two different regimes, the first anticyclonic and the second cyclonic. Although the two regimes were not separated temporally by more than 10 days or so, we treated the trajectory as two separate eddies because they were of opposite rotational sense.

\section{$2.3 \quad$ Results}

\subsubsection{General Results}

This section is intended to provide estimates of the eddies' gross characteristics. Abundances, lifetimes and depths are discussed, along with results of the fitting technique above, which produced estimates of size, velocity, Rossby number, and direction of rotation. Table 2.2 shows these parameters for each eddy.

Considering the trajectory records from all 153 floats, and assuming the total number of reliable days is about $87,000,7.6 \%$ (or about 1 in 13 ) of float days were spent looping. Of the shallower floats (shallower than $3300 \mathrm{~m}$ ), $5.7 \%$ of all days (or $10.0 \%$ of strictly good days) were spent looping, and for the deeper floats, these numbers are $5.3 \%$ (and $8.3 \%$ ).

In contrast with McWilliams' 1985 statement that the vast majority of SCVs are anticyclonic, in this basin, about an equal number of cyclonic and anticyclonic eddies were identified in float trajectories. Of the 34 eddies tracked, 19 were cyclonic (clockwise) and 15 


\begin{tabular}{|c|c|c|c|c|c|c|c|}
\hline Float & $\begin{array}{r}\text { Pressure } \\
(d b) \\
\end{array}$ & $\begin{array}{l}\text { Frequency } \\
\text { (cycles/day) }\end{array}$ & $\begin{array}{r}\text { Record Length } \\
(\text { days })\end{array}$ & $\begin{array}{r}\text { Radius } \\
(\mathrm{km}) \\
\end{array}$ & $\begin{array}{r}\text { Mean Speed } \\
(\mathrm{cm} / \mathrm{sec})\end{array}$ & $\begin{array}{r}\text { Swirl Speed } \\
(\mathrm{cm} / \mathrm{sec})\end{array}$ & $\begin{array}{r}\text { Direction } \\
(C C W \text { from east }) \\
\end{array}$ \\
\hline $38 \mathrm{a}$ & 2380 & -0.072 & 174 & 20 & 2.4 & 10.2 & $250^{\circ}$ \\
\hline 60 & 2620 & -0.027 & 172 & 19 & 1.7 & 3.7 & $230^{\circ}$ \\
\hline 64 & 2600 & -0.103 & 152 & 29 & 4.1 & 21.8 & $340^{\circ}$ \\
\hline 85 & 2580 & -0.015 & 166 & 28 & 1.1 & 3.1 & $10^{\circ}$ \\
\hline 153 & 2470 & -0.190 & 252 & 11 & $\overline{1.9}$ & 15.3 & $\overline{90^{\circ}}$ \\
\hline $178 b$ & 3830 & -0.029 & 102 & 20 & 1.1 & 4.1 & $10^{\circ}$ \\
\hline 180 & 3820 & -0.070 & 200 & 5 & 0.4 & 2.5 & $240^{\circ}$ \\
\hline $195 a$ & 2470 & -0.036 & 208 & 15 & 0.9 & 3.8 & $200^{\circ}$ \\
\hline $197 \mathrm{a}$ & 2420 & -0.198 & 190 & 14 & 1.2 & 19.6 & $350^{\circ}$ \\
\hline $209 a$ & 2610 & -0.037 & 490 & 11 & 0.4 & 3.0 & $180^{\circ}$ \\
\hline $209 c$ & 3480 & -0.052 & 196 & 7 & 0.5 & 2.5 & $90^{\circ}$ \\
\hline 250 & 1960 & -0.057 & 150 & 7 & 1.7 & 2.9 & $140^{\circ}$ \\
\hline 288 & 3770 & -0.028 & 112 & 22 & 3.1 & 4.5 & $120^{\circ}$ \\
\hline $291 b$ & 2250 & -0.047 & 154 & 18 & 3.5 & 6.2 & $190^{\circ}$ \\
\hline $291 \mathrm{c}$ & 2260 & -0.036 & 188 & 19 & 1.6 & 4.9 & $200^{\circ}$ \\
\hline $38 \mathrm{~b}$ & 2440 & 0.027 & 98 & 23 & 0.9 & 4.4 & $180^{\circ}$ \\
\hline 49 & 2670 & 0.050 & 238 & 18 & 1.1 & 6.5 & $150^{\circ}$ \\
\hline $84 a$ & 3770 & 0.035 & 94 & 14 & 0.3 & 3.5 & $120^{\circ}$ \\
\hline $84 \mathrm{~b}$ & 3900 & 0.016 & 214 & 15 & 0.5 & 1.7 & $270^{\circ}$ \\
\hline 142 & 3930 & 0.028 & 110 & 19 & 1.0 & 3.9 & $220^{\circ}$ \\
\hline $178 \mathrm{a}$ & 3830 & 0.067 & 106 & 11 & 1.3 & 5.6 & $120^{\circ}$ \\
\hline 188 & 2840 & 0.048 & 610 & 12 & 1.1 & 4.3 & $250^{\circ}$ \\
\hline 189 & 3770 & 0.024 & 198 & 5 & 0.2 & 0.9 & $30^{\circ}$ \\
\hline 194 & 3380 & 0.046 & 154 & 20 & 0.7 & 6.7 & $270^{\circ}$ \\
\hline $195 \mathrm{~b}$ & 2470 & 0.038 & 116 & 10 & 0.6 & 2.8 & $30^{\circ}$ \\
\hline $197 \mathrm{~b}$ & 2400 & 0.061 & 50 & 31 & 0.9 & 14.0 & $320^{\circ}$ \\
\hline 238 & 3630 & 0.010 & 362 & 68 & 1.1 & 4.7 & $250^{\circ}$ \\
\hline 246 & 3810 & 0.037 & 142 & 13 & 0.8 & 3.4 & $90^{\circ}$ \\
\hline 247 & 3790 & 0.007 & 362 & 28 & 0.3 & 1.5 & $170^{\circ}$ \\
\hline 248 & 3750 & 0.016 & 262 & 25 & 0.1 & 2.8 & $300^{\circ}$ \\
\hline 286 & 3700 & 0.015 & 320 & 27 & 1.1 & 2.3 & $270^{\circ}$ \\
\hline 289 & 3630 & 0.040 & 116 & 16 & 1.7 & 4.7 & $190^{\circ}$ \\
\hline 290 & 3710 & 0.025 & 130 & 15 & 0.7 & 2.6 & $300^{\circ}$ \\
\hline $291 \mathrm{a}$ & 2250 & 0.052 & 98 & 21 & 1.8 & 8.0 & $220^{\circ}$ \\
\hline
\end{tabular}

Table 2.2: The depths, rotation frequencies, record lengths, radius estimates, mean speeds, swirl speeds, and directions of propagation of the tracked eddies are shown. Negative (positive) frequencies denote anticyclonic (cyclonic) rotation. Direction of motion is the direction of net displacement, and is in degrees counterclockwise from east. 
were anticyclonic. Periods of rotation range from 5 days to 138 days, and average 35 days. The highest periods are probably erroneous, as they were calculated from float trajectories with segments of position data missing, where a straight line inserted into the trajectory between loops, probably replacing a true looping trajectory. Swirl speeds range from 1 to $22 \mathrm{~cm} / \mathrm{sec}$, and average $6 \mathrm{~cm} / \mathrm{sec}$.

While the total number of cyclones found is almost equal to the total number of anticyclones, this equity does not hold in each of the two depth ranges. Most of the looping floats deeper than $3000 \mathrm{db}$, indeed $76 \%$, were in cyclonic eddies, while $65 \%$ of the shallower eddies were anticyclones.

Although the true spatial extent of each eddy cannot be determined from the data obtained by one tracking float, the fitting procedure does provide a lower limit on the eddy radius. For the 34 eddies studied, this lower limit (the maximum radius observed during the time series) ranges from $7.4 \mathrm{~km}$ to $69.9 \mathrm{~km}$, with one additional outlier of $189.3 \mathrm{~km}$. Mean and median values are $32.3 \mathrm{~km}$ and $25.7 \mathrm{~km}$, respectively. (This outlier corresponds to a float which recorded an average radius of under $70 \mathrm{~km}$, but during one fitting interval, the fitting procedure produced this anomalously high radius value.) The only indication of vertical size of the observed eddies comes from floats 188 and 209, both of which experienced drop weight flooding events. Both indicate that the eddies (one cyclone and one anticyclone) were at least $1000 \mathrm{~m}$ in vertical extent.

The number of consecutive days spent looping provides a lower limit on eddy lifetimes. It is not possible to discern the true lifetimes because floats may start or stop looping due to entrainment or detrainment, not exclusively due to formation or destruction events, and because some floats were deployed directly into eddies or happened to be in an eddy 
immediately prior to resurfacing. Looping durations range from 50 to 610 days, with a mean and median values of 197 and 169 days, respectively. Included in these totals are 7 cases in which the time series begins or ends while the float is in the eddy. In 6 cases (floats 38.1 , 180, 188 194, 209.1, and 286), it appears that the float was deployed directly into an eddy. One of these floats, float 188, was the longest lived eddy, at 610 days. The eddy it tracked evidently lived even longer. In the case of float 250 , the record ends while the float is still in the eddy.

Rossby numbers were estimated for the 34 tracked eddies. These were calculated as the relative vorticity (calculated assuming the eddies are in solid body rotation, as twice the angular velocity, estimated from fit parameters) divided by the local coriolis parameter. If the float was trapped in the eddy's core, which is indeed in solid body rotation, then the estimate of the vorticity is accurate. If the float was instead trapped outside of the core, where speeds taper down with increased distance from the eddy center, then the vorticity estimate is low. Thus, the calculated Rossby number should be regarded as the lower limit of the structure's true Rossby number. The maximum and minimum calculated are 0.79 and 0.02 , and the mean is 0.17 . This means that in the horizontal momentum equation, the acceleration term is about two tenths the size of the coriolis term, and in some cases much larger, invalidating the quasi-geostrophic assumption.

The Burger number for these features was also estimated. The Burger number is the square of the ratio of the Rossby and Froude numbers, or $\left(\frac{2 N H}{R f}\right)^{2}$, where $N$ is the buoyancy frequency, $H$ is the half depth of the feature, and $R$ is the radius. Taking $N \sim 6 * 10^{-4} \sec ^{-1}$, $H \sim 2000 m$ (the half depth of the features according to hydrographic data discussed below), $R \sim 30 \mathrm{~km}$, and $f \sim 10^{-4} \mathrm{sec}^{-1}$, we find that the Burger number is about 0.6 , meaning that 


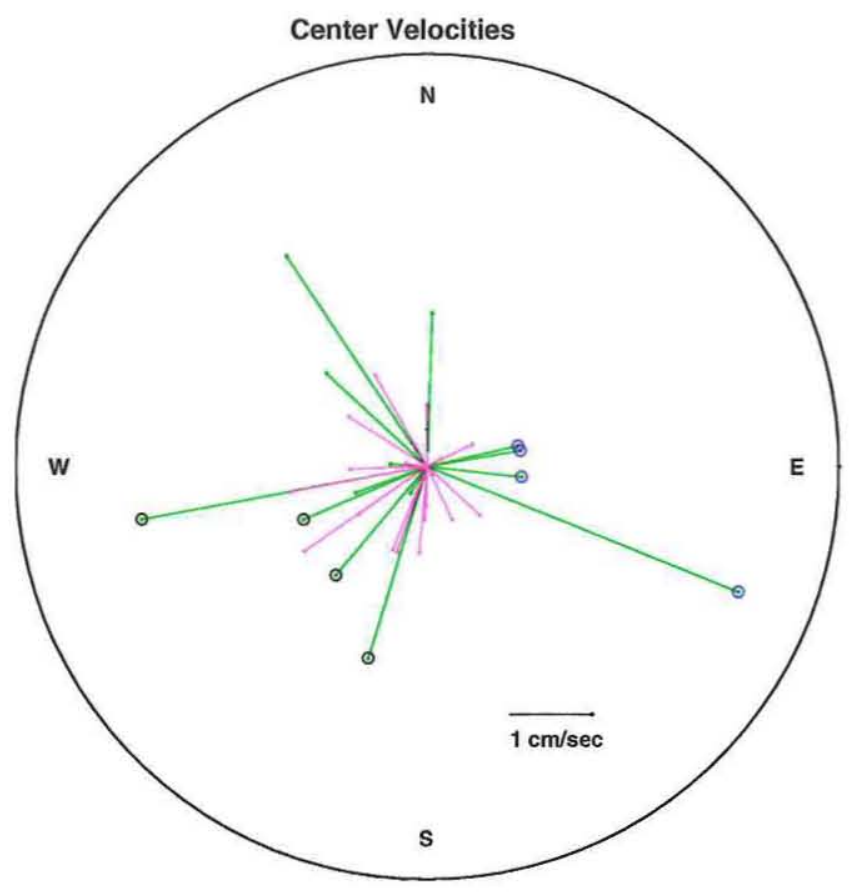

Figure 2.2: Shown are vectors representing the total displacement divided by total time for each looping float. Green lines represent anticyclones, and magenta represent cyclones. Blue and black circles mark eddies (all anticyclones) whose direction of travel disagrees with expectations.

the vertical stratification is important.

\subsubsection{Translational Velocities}

Figure 2.2 shows the direction and speed with which the eddy centers move, and distinguishes between cyclonic and anticyclonic eddies. This section will discuss expected and observed trends in eddy translation.

Eddies are widely believed to translate westward at approximately the Rossby wave speed. This is confirmed by several numerical and theoretical studies (McDonald and Straub, 1995). But because ambient potential vorticity gradients restrict meridional motion, the 
north and south component of these translational velocities are more difficult to explain. Below are a few of the theories put forth to account for the meridional motion of SCVs. These examples rely on either advection, mixing, or coupled dissipation and nonlinear effects.

Richardson et al. (1989) and Hogg and Stommel (1985 and 1990), proposed two different mechanisms for advection to account for the eddy translation. Richardson et al. suggested simple bulk advection, assuming that meddies extended vertically into regions of faster flows, which carried the features along. The idea of bulk advection, in addition to being the simplest first guess, was supported by a pair of floats in the LDE program, which were at nearly equal depths and horizontally proximate. One float was trapped in an SCV, and the other was carried along at a velocity that matched the apparent eddy center velocity (Riser et al., 1986). More recent data (particularly from meddies) clearly shows displacement compared to surrounding water masses (McDonald \& Straub, 1995). The present study confirms that floats in eddies translate much more quickly that the mean flow, particularly at depth. Hogg and Stommel, however, proposed an advection mechanism without substantial currents at the depth of the SCV. This involves a second eddy, located above the primary eddy, which is locked to the deep eddy. Their 1985 paper discusses the pair moving under the influences of each other, without any larger scale current. Hogg and Stommel (1990) discuss the locking of the shallower eddy onto an advective flow, allowing both eddies to be carried along by the shallow flow. I am not aware of any observational confirmation of this additional eddy, but Walsh (1992) suggests that even an asymmetry or tilting of the eddy could produce a similar effect. Additionally, Flierl et al. (1980) show that a quasi-geostrophic soliton generates a horizontally adjacent "rider" eddy, which influences propagation. This generation of a second eddy has also been observed in numerical models 
(Claudia Schmid, personal communication).

Beckmann and Kase (1989) were able to reproduce the bulk south-southwest-ward motion of a particular meddy with a QG spectral model which incorporates small scale dissipation. They explain dynamically why the model behaved this way, showing that nonlinearities in the QG equations cause instability events which both deform the (initially circular) shape of the eddy and deflect it southward. However, most observations of SCVs (including this study) show remarkably circular trajectories, casting doubt on this explanation.

Colin de Verdiere (1992) and McDonald and Straub (1995), each present variations on another possible explanation: mixing. Colin de Verdiere notes that a lens is an anomalously thick or thin region in a density layer, and the end of the eddy's life is marked by the elimination of this anomaly, when the thickness matches the ambient stratification horizontally adjacent to it. This, he argues, occurs mainly because of lateral mixing within the deformed layer, causing the water columns in convex lenses to become vertically shorter (taller in the case of concave lenses), requiring equator-ward (or pole-ward) motion to conserve vorticity. Crucial to his observational confirmation of this theory is the requirement that relative vorticity is conserved, and while data is ambiguous with regards to this question, McDonald and Straub (1995) note that there is no dynamical constraint requiring it. They instead propose that diapycnal mixing is the culprit, suggesting that mixing above and below the eddy not only plays a role in dissipating the eddy, but also in stretching or compressing water columns vertically surrounding the eddy, and inducing background velocities which effect the eddy velocity.

For the case of cyclonically rotating Brazil Basin SCVs, the observed direction of translation is consistent with the above predictions (see figure 2.2). We observe a tendency 
for the eddies to translate to the southwest. It should also be noted that float 188 was deployed directly into an eddy, and hydrographic data indicates that the eddy was closely paired with an anticyclonic partner located north of it. The geometry allows us to predict an eastward velocity for the pair. Indeed, float 188 travels eastward for several days after deployment, but then heads southwest-ward for the remainder of its looping duration.

The anticyclones are much more erratic; they do not appear to show a common tendency toward any direction of propagation. While some move northwest, four move southwest, and four move east. These unexpected trajectories are shown as figure 2.3 , which is suggestive of advection playing at least some role in translation. The four south-westward translating eddies were all located near the western boundary and traveled roughly parallel to isobaths. It is well known that a southward flowing deep western boundary current (DWBC) is located there (De Madron and Weatherly, 1994). It is unclear why the others move eastward. They, too, are located near the western boundary, and near steep bathymetry, and are therefore located in the region where fast advective flows are most likely. Hogg and Owens (1999) note that the basin's interior regions are dominated by zonal velocities, which may be responsible for advecting these eddies.

We would expect advection to play an equally significant role in the motion of cyclones. Perhaps the south-westward and westward motions exhibited by the cyclones is due, in part, to advection by the south-westward flowing DWBC or interior flows. The absence of eastward propagating cyclones could be due to the small sampling size. 


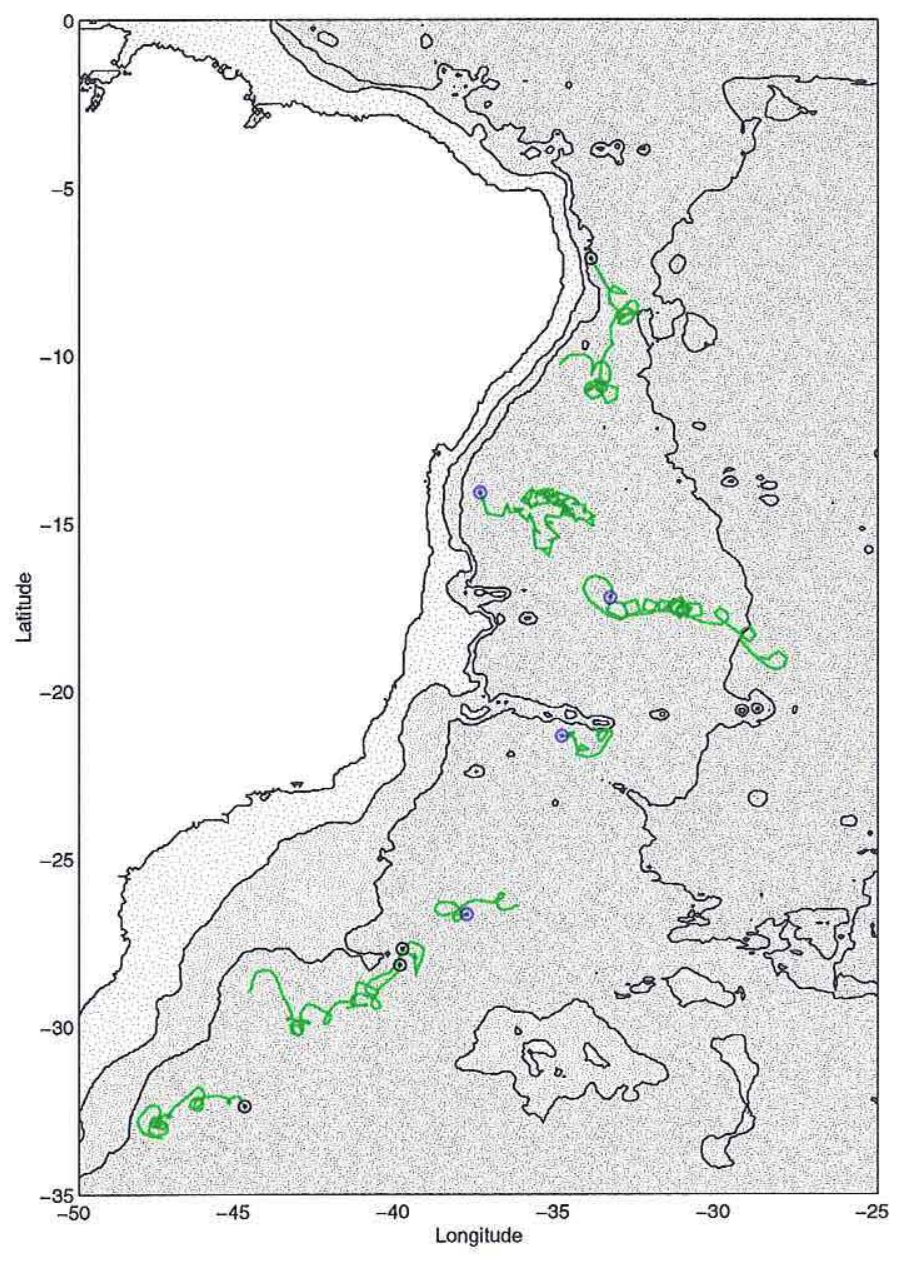

Figure 2.3: Trajectories of anticyclones which translated in unexpected directions are shown. The locations and south-westward motion of those whose starting points are shown in blue suggest advection by the deep western boundary current. The eastward motion of those shown in black is not as easily explained. 


\subsubsection{Bathymetry}

It is necessary to note another interesting feature of the eddy trajectories. This is the apparent tendency of looping behavior to start or end near seamounts. The discussion that follows is a very cursory, qualitative interpretation of the available data.

Bathymetry may play a role in either formation and destruction events and/or trapping and release of floats. Float trajectories and bathymetry $\left(5^{\circ}\right.$ by $5^{\circ}$ ETOPO5 data obtained through the USGS) reveal about 27 events where a tracked eddy was within $60 \mathrm{~km}$

of a significant (300 $\mathrm{m}$ high or higher) seamount. In 11 cases, the eddy remained apparently unaffected by the seamount. In 6 cases ( 5 cyclonic and 1 anticyclonic), looping began near the seamount. Figure 2.4 shows one such instance. Further, 4 anticyclonic and 4 cyclonic eddies stopped looping near seamounts. In 2 additional cases, cyclones appeared nearly stationary adjacent to a seamount, with the floats both beginning and ending looping within $60 \mathrm{~km}$ of the seamount (see figure 2.5 ).

Huppert and Bryan (1976) showed how an unsteady flow over a seamount can produce two eddies. One column of water is displaced from a deep region to the top of the seamount, where, because it is compressed, it becomes a stationary anticyclone. Another column, displaced from the top of the seamount and stretched to reach the ocean floor, evolves into a shed cyclone. We don't, however, observe a tendency for cyclones to be stationary.

It is not clear, however, that the beginning or end of looping necessarily indicates formation or destruction events (Shapiro et al. 1997). It is possible that these events represent only the capture or release of floats into or out of the eddies. Shapiro suggests that when the background flow decreases relative to the translational eddy velocity, the 


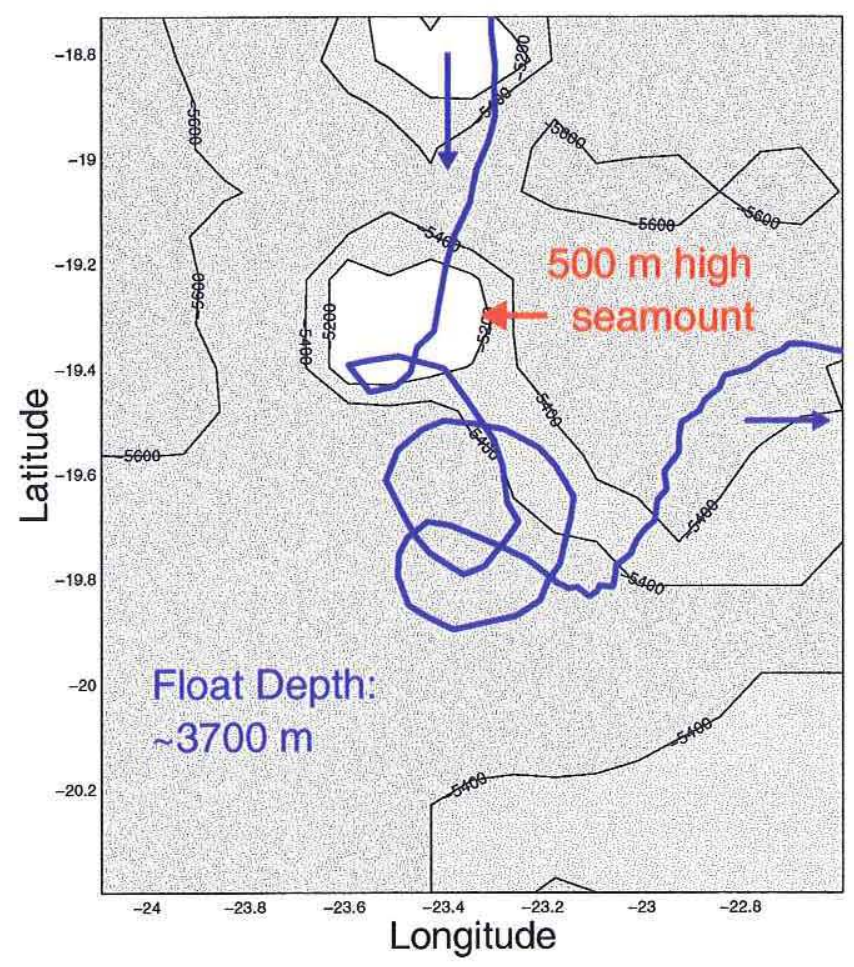

Figure 2.4: The track of this float shows looping which begins above a seamount. One possible explanation for eddy formation is that the water column is stretched as it descends a seamount, and, to conserve angular momentum, it begins to spin. 


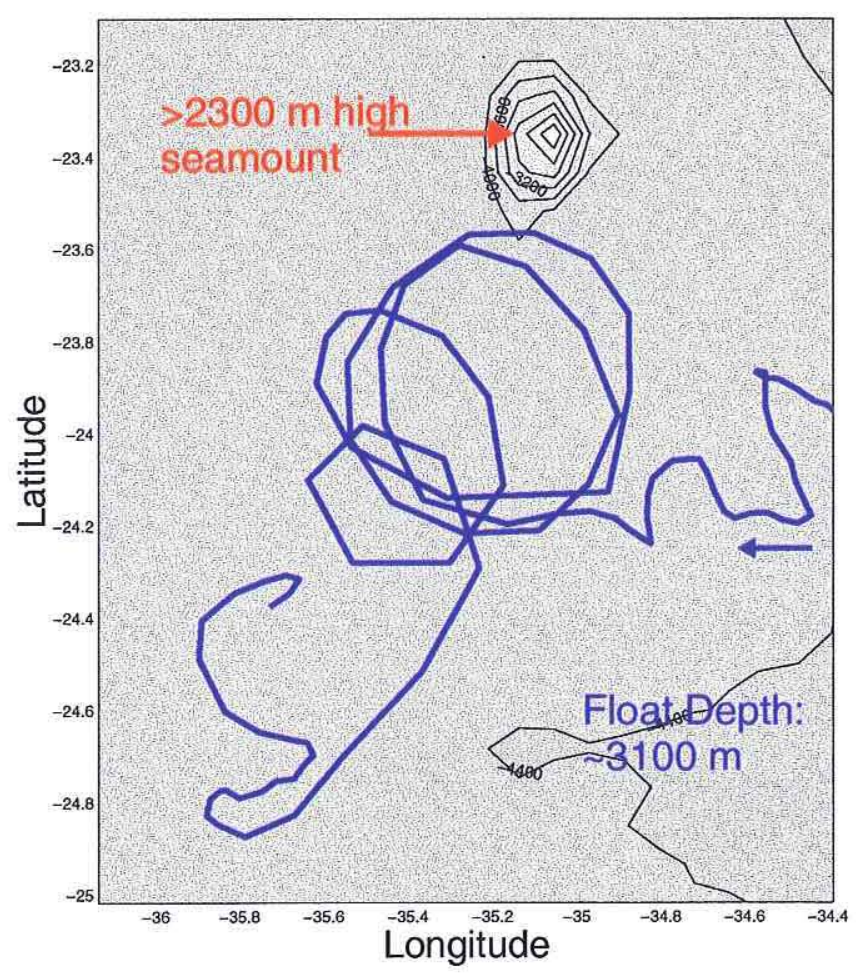

Figure 2.5: This float's trajectory shows looping which begins and ends close to the same seamount. 
eddy's "trap zone" increases in size, causing water parcels which may have been initially located outside of the trap zone to begin spinning with the eddy. Similarly, parcels of water or floats may be released when the background flow strengthens. He suggests horizontal velocity shear as the primary mechanism by which the background flow and the eddy itself can change speeds relative each other. Horizontal velocity shear is likely to be enhanced over seamounts, where friction may slow the bottom of a jet.

\subsubsection{Temperature}

Temperature time series for 2 looping floats (153 and 64, both of which were trapped in anticyclones) indicate increased temperatures while looping. Pressure records verify that this change was not related to a corresponding change in depth. None of the floats experienced a similar, but negative, change in temperature. These paragraphs will discuss these events, as well as discuss comparisons of all looping float temperatures with with local hydrographic temperature data. This analysis leads to the suggestion that many of the floats calibration problems, resulting in erroneous temperature records.

Figure 2.6 shows time series of temperature recorded by several floats. Floats 153 and 64 experienced sudden temperature changes temporally coincident with the beginning of looping. These two events are illustrations of the isobaric nature of the floats. Strictly, the floats are not Lagrangian, as they are unable to track a parcel of water which moves substantially in the vertical. Here we see clearly that each float stopped tracking one parcel and began tracking another. These floats were probably entrained into existing eddies, or at least certainly entrained into an anomalous water mass at the start of looping. 
Float 64
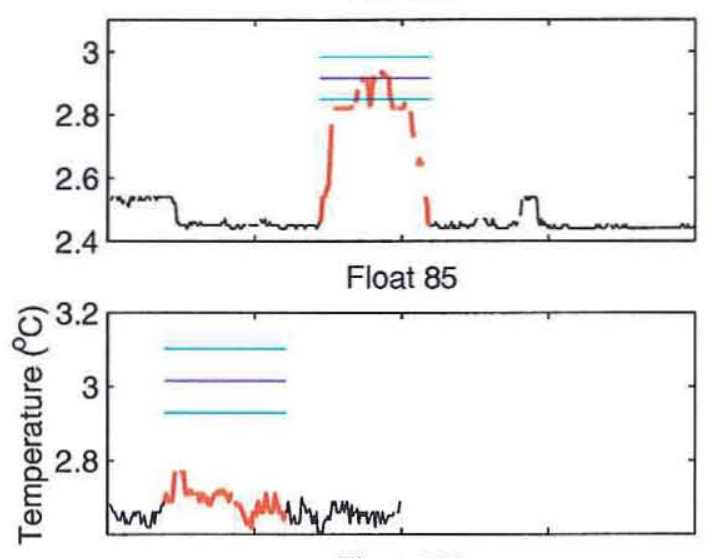

Float 188

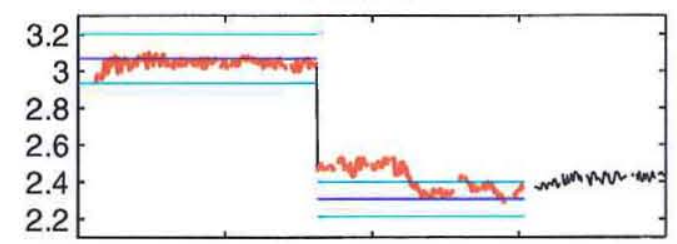

Float 290

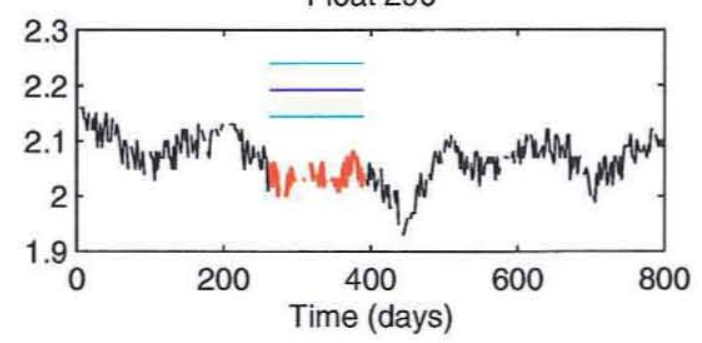

Float 84

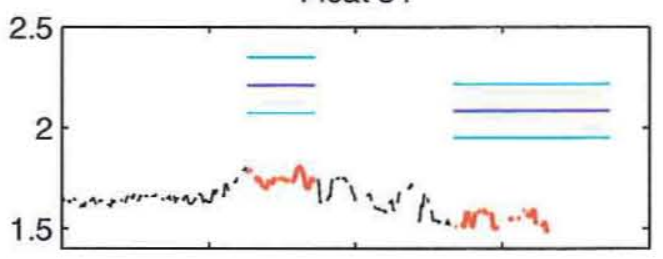

Float 153

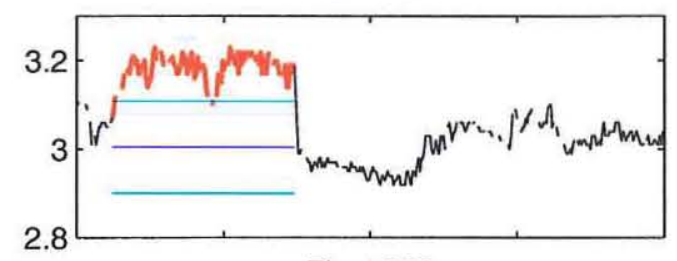

Float 289

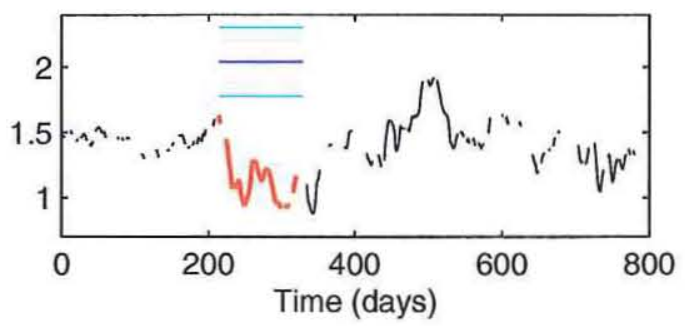

Figure 2.6: Temperature records are shown for several floats. The record is shown in red when the float was determined to be in an eddy. Blue and cyan lines delineate the local mean temperature (as determined from nearby WOCE hydrographic stations), and one standard deviation. These plots suggest that early difficulties in temperature calibration were never fully resolved. 
While the information provided here is only qualitative, it is tempting to guess what the geometry of the eddies may be. Perhaps these anticyclones exhibit the classic meddylike shape: isopycnals bowed out vertically such that the eddy is centered on a minimum in stratification. This corresponds to vertically bowed out isotherms if the water involved is local. Then in these two cases, we conclude that the float was entrained into the bottom half of the eddy. The fact that we see no cooling temporally coincident with the start of looping could be attributed either to chance (a float could as easily have gotten entrained into the top of an eddy, and then would have recorded a decrease in temperature when looping began), or to the vertical distribution of eddies (perhaps all eddies are centered shallower than $2500 \mathrm{~m}$, where the shallowest floats are located). But maybe the fact that no floats exhibit cooling when looping starts is instead caused by a slightly different geometry. Perhaps the dynamically necessary bowing out of isopycnals is not associated with a simple bowing out of isotherms. If the water in the eddy is anomalous compared to local water (if it is in a different place on a $\theta$-S diagram), then salinity could be influential in the shape of isopycnals. This could result in a simple convex lens in density, even while eddy temperature is at every depth higher than or equal to the water horizontally around it. Such a scheme could account for the lack of any evidence of cooling of a float at the time looping initiated. Some eddies may be formed remotely, and therefore contain water with anomalous properties.

Besides these two striking examples, no other floats exhibited such clear changes in temperature when looping began. It is possible, though, that some floats were in locally warm water. I attempted to determine systematically whether or not the floats were in warmer water than is locally typical by using hydrographic data. The nature of this data, and the geographical boxes into which they were binned, is discussed in detail in the next 
chapter. Briefly, data was divided into approximately $5^{\circ}$ squares, or larger boxes if necessary. I determined the mean location (ie., chose one box) and depth of the float, and found the local mean temperature within that box by linearly interpolating between hydrographic stations in the vertical, and by simple averaging with the horizontal. For this analysis, only WOCE data were used.

This analysis produced some surprising results. For some floats, the results are shown in figure 2.6. One example, float 64 , shows a clear increase in temperature temporally coincident with the start of looping. It appears to be several standard deviations colder than surrounding waters before and after looping, and approximately the same temperature as surrounding water while looping. The hydrographic data upon which this is based are reliable: the stations surround the float location geographically, and are of good quality and high resolution. I cannot imagine an eddy geometry consistent with these data. It is more likely that one measurement is in error, and since the hydrographic data are numerous and self-consistent, the float temperature is suspected. The problem is probably not limited to this particular float. As figure 2.6 shows, five floats $(64,84,85,289$ and 290$)$ exhibit temperatures about $0.2^{\circ}$ to $0.4^{\circ}$ below the local mean when they are not looping. These offsets are consistent with a known problem in the temperature calibration procedure. This problem precludes a comparison of float temperatures to local temperatures (obtained from hydrographic data).

Also shown are 2 additional floats of special interest: 153 and 188. If accurate, the hydrographic and Lagrangian data near the location of Float 153 confirm our initial hunch; that the float is in locally typical water except when looping, when it is in water about 2 standard deviations warmer. For this and other floats, there is no indication that 
the float-recorded temperature is in error. Float 188 appears, at first glance, to have correct measurements as well, as temperatures recorded while looping are within about one standard deviation of the local mean. I note this here in anticipation of a discussion regarding the hydrographic data taken when float 188 was deployed.

\section{$2.4 \quad$ Float 188}

Float 188 has already been recognized for being deployed directly into an eddy, for having the longest time span of continuous looping, and for having experienced a flooded drop weight, corresponding to a sudden increase in depth. It was deployed (and immediately began looping) on a WOCE hydrographic cruise. This is the only case in which hydrographic data is available for a tracked eddy. The hydrographic data is of additional interest because it shows an unexpected, perhaps pathological case: the eddy was one of a pair of eddies of opposite rotational sense, meridionally aligned, and quite close together.

\subsubsection{Float Data}

The available data from float 188 is shown as figure 2.7. The float's trajectory, along with time series of temperature and pressure, are shown. The most striking features are summarized here. Float 188 was deployed directly into an eddy, and then experienced the longest uninterrupted period of looping of any float, at 610 days. It experienced an appreciable change in frequency temporally coincident with a sudden increase in pressure, assumed due to a flooded drop weight. This indicates that the eddy was at least $1000 \mathrm{~m}$ in vertical extent, with significant vertical shear. The eddy was a cyclone which moved $580 \mathrm{~km}$ south- 

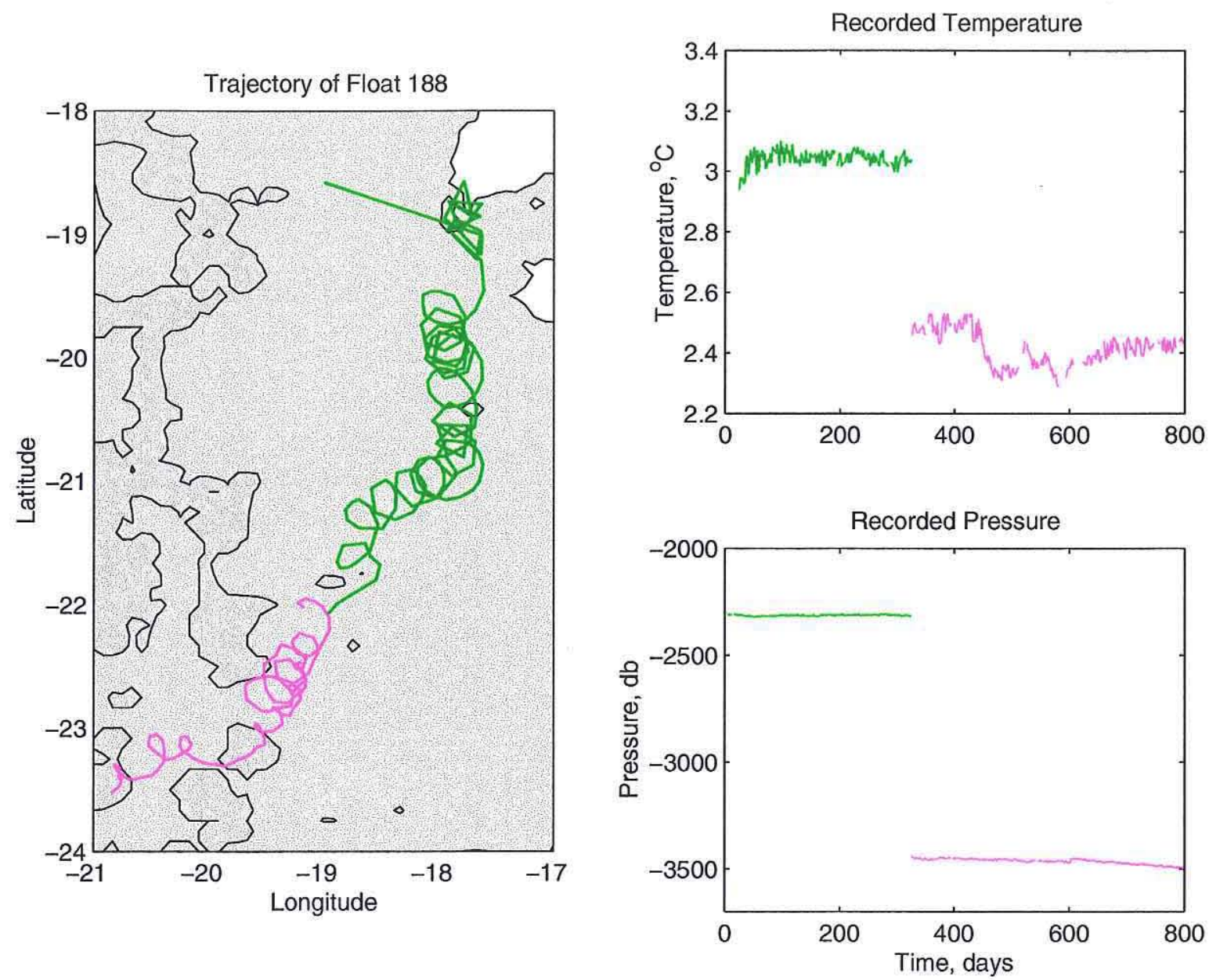

Figure 2.7: The trajectory of float 188 is shown, along with temperature and pressure records. The 4000 and $5000 \mathrm{~m}$ isobaths are shown, with shallower waters located to the east.

southwest (corresponding to a translational speed of $1.1 \mathrm{~cm} / \mathrm{sec}$ ). The eddy had a swirl speed of approximately $4.3 \mathrm{~cm} / \mathrm{sec}$.

Because the float temperature data has already proved unreliable, it is hard to discern whether or not the float was in locally anomalous water, temperature-wise. No pre-looping float temperature can be established with certainty, although there is some indication early in the temperature record of an increase in temperature, perhaps coincident with entrainment. Figure 2.6 seems to indicate (if indeed the float's recorded temperature is accurate) that the eddy is composed of locally typical (or perhaps slightly warm) water, at least at the two 
depths occupied by the float. It should be noted that, due to data transmission dropouts, the earliest temperature reported by the float occurs 26 days after deployment.

\subsubsection{Hydrographic Section}

Float 188 was deployed while a hydrographic section was being taken, and section exhibits a very interesting geometry, as was initially called to our attention by Georges Weatherly (personal communication). Figure 2.8 summarizes the hydrographic data taken along $19^{\circ}$ West when float 188 was deployed. The data used is available through the WOCE Hydrographic Program office at Scripps Institute of Oceanography. Sections of potential density (referenced at $2000 \mathrm{db}$ ), potential temperature, in situ temperature (shown to allow comparisons between float-measured temperature and CTD-measured temperature), and salinity are shown, along with the initial float location, and the local ambient stratification (determined from hydrographic data taken within the rectangle $17.5^{\circ}$ to $22.5^{\circ}$ South, $17.5^{\circ}$ to $27.5^{\circ}$ West). The vertical dashed lines indicate the locations of hydrographic stations, where data was taken at $2 m$ intervals in the vertical. I have designated with blue what appears to be a concave lens, and with red a convex lens. The other panels show profiles of these same variables. Again, the concave lens is in blue, the convex lens is in red, and here the local mean profiles are in black.

The initial striking aspect of the potential density distribution is the presence of not one but two eddies. The northern-most lens is an anticyclonic convex feature, resembling the SCVS McWilliams (1984) describes. The other is characterized by isopycnals pinched together, and corresponds to cyclonic rotation. The trajectory of float 188 clearly shows 

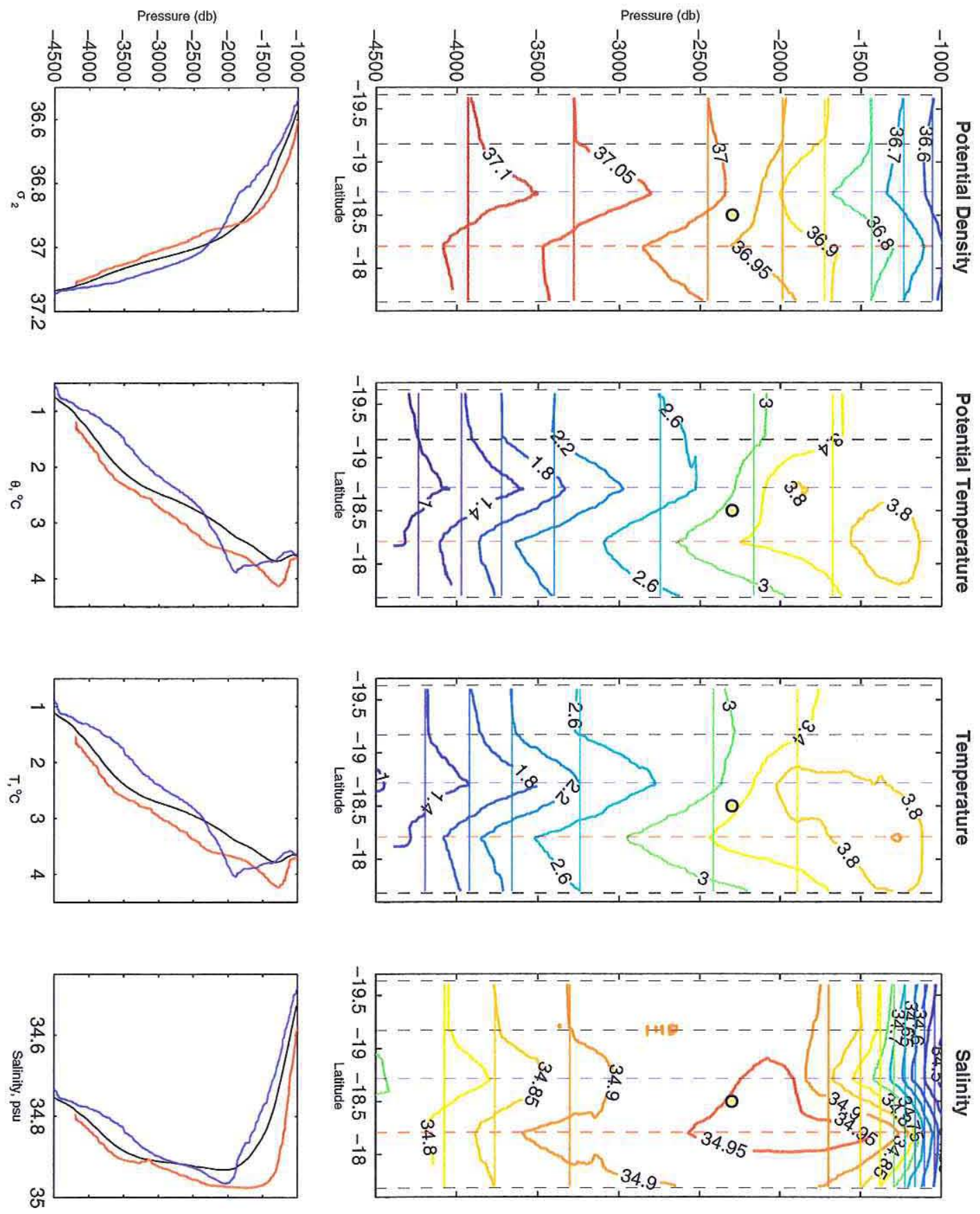

Figure 2.8: Hydrographic data is shown for the eddy associated with float 188. Vertical sections and profiles are shown of potential density (referenced at $2000 \mathrm{db}$ ), potential temperature, in situ temperature (shown to allow comparison with float-measured temperature) and salinity. Both the horizontal lines in the sections and the black lines in the profiles represent box-wide averages determined from WOCE hydrographic data. Vertical dotted lines show where data was taken, with red representing the convex lens and blue representing the concave lens. The location where the float was deployed is shown in yellow. Note that initial in situ float temperatures, according to float data and hydrographic data, disagree (see figure 2.6). 
cyclonic rotation, indicating that the float was caught in the concave, southern-most lens.

The presence of this pinch in isopycnals, hinted at by Lagrangian records of cyclonic SCVs, is at odds with McWilliams' (1984) statement that cyclonic SCVs are exceedingly rare. While this is the only instance of such a feature verified by both Lagrangian and hydrographic data, our Lagrangian data contains roughly equal populations of cyclones and anticyclones, indicating that this cyclone is not an exceptional eddy. Rather, this basin hosts as many of them as it does anticyclones. It is unclear what mechanism is responsible for their formation, but the mechanism whereby mixing is following by geostrophic adjustment must not be the primary formation scenario in this basin. Rather, a mechanism capable of making equal number of convex and concave lenses, and of making pairs as seen here is necessary. Baroclinic instability is one such mechanism.

Looking at the potential density profiles in figure 2.8 , we are able to compare the local mean stratification with the convex lens, in which density remains largely unchanged over an extended vertical distance, and the concave lens, in which density changes very abruptly over the same range. While in this case temperature and salinity also show a marked departure from surrounding values, it is the density profile which is most closely linked to the dynamics. These density profiles provide us with a criterion for identifying SCVs in hydrographic data taken in the Brazil Basin.

Another very interesting aspect of this density section is that it shows the pair of eddies so horizontally proximate as to influence each other's motion. Indeed, the initial velocity record of float 188 suggests that the float moves eastward, as expected of a pair of eddies with this geometry. Unfortunately, aside from the deployment location, the float's position is not known until about the 26th day. But within this first month, it moved 152 
$k m$, in a direction $18^{\circ}$ south of east. The float information, which shows an initial eastward translation, along with the geometry shown, imply that one mechanism of eddy translation is the interaction of adjacent eddies.

But it is not only the density distribution which is intriguing here. Notice that the convex lens is warmer and saltier than the local average at virtually every depth, and the concave lens is also very anomalous, although the sign of the anomaly changes with depth. This suggests that this eddy pair was not generated locally.

Finally, note one additional observation regarding figure 2.8. Above, it was determined that the float recorded temperatures consistent with the local mean, suggesting that perhaps the float was recording temperature correctly. The temperature record shows an early increase in temperature of about $0.1^{\circ} \mathrm{C}$ (perhaps conincident with entrainment, consistent with the increase in temperature other floats measured when looping began). However, the float never records temperatures above about $3.1^{\circ} \mathrm{C}$. Although they are poorly resolved in the horizontal, these concurrent hydrographic data suggest that the float was actually deployed into water significantly warmer than that, between 3.3 and $3.4^{\circ} \mathrm{C}$, suggesting that this float's temperature record was also contaminated by calibration errors.

\subsection{Conclusions}

In the deep Brazil Basin, about 1 in 13 float days is spent looping in an SCV. These structures are about $30 \mathrm{~km}$ in radius, and perhaps $1000 \mathrm{~m}$ vertical scale. They have translational velocities of about 1 to $4 \mathrm{~cm} / \mathrm{sec}$, and swirl speeds between 1 and $22 \mathrm{~cm} / \mathrm{sec}$. Half are

cyclones and half are anticyclones, and hydrographic data taken at the site of deployment of 
one of the floats suggests the existence of both convex and concave lenses. Lagrangian data suggests that the eddies contain anomalously warm water, and hydrographic data show one convex and one concave lens, both of which are enriched in warm, salty water.

Thus far, several eddies have been identified in float data, and one has been examined using both float and hydrographic data. The density profiles found in connection with this eddy provide criteria to search for SCVs in hydrographic data. This search is the topic of the following chapter. 


\section{Chapter 3}

\section{Hydrographic Studies}

Using both the hydrographic data taken in one tracked eddy, and the vast quantity of hydrographic data available for the Brazil Basin, we were able search for SCVs in strictly eulerian data. The section taken when float 188 was deployed suggests that Brazil Basin SCVs have anomalous density stratification, salinity and temperature. Using these clues, we searched for these features in other hydrographic data to determine the population of SCVs and whether they contain warmer, saltier water. This chapter presents the methods used in this search and presents the results of the study.

\subsection{Datasets}

We used hydrographic data from the Brazil Basin from two sources: the HydroBase records and WOCE section data. These sources differ greatly from one another, particularly in the geographic sampling patterns, the temporal distribution, and the vertical resolution. Because the nature of the data is important in deciding upon an eddy search technique 
and in interpreting the results, both sets are discussed below. In both cases, we used only pressure, temperature, and salinity information.

\subsubsection{HydroBase data}

HydroBase is a database of historical hydrographic data. For a complete review of its contents and of the quality standards used in compiling it, see Curry (1996). For our purposes, this summary will highlight the most important aspects. Data is included which was collected over a long period of time, throughout the twentieth century. The version we used had not yet been updated to include WOCE section data. The data we used has been quality controlled, so that extreme outliers in salinity or temperature are not included as they were supposed due to erroneous measurements. This may be important for our study, because eddies are likely composed of anomalous water masses. If eddies exist that are outside these generous limits in salinity and temperature, we may find only an incomplete list of eddies.

We examined deep data taken between 10 and $50^{\circ}$ West, and between the equator and $40^{\circ}$ South. HydroBase contains 1040 stations in this geographical area which extend to at least $1000 \mathrm{db}$ in depth. Because it is primarily bottle data, the vertical resolution is coarse; the available stations contain between 1 and 45 points (the average being 12 points) beneath the $1000 \mathrm{db}$ level. The geographic location of each station used is shown in figure 3.1, as are the boxes over which the data were averaged for analysis. Notice that the horizontal resolution along any ship track is low, and the stations appear very scattered, rather than delineating clear tracks. This precludes finding any pairs of SCVs in close proximity as were seen near the deployment site of float 188. 


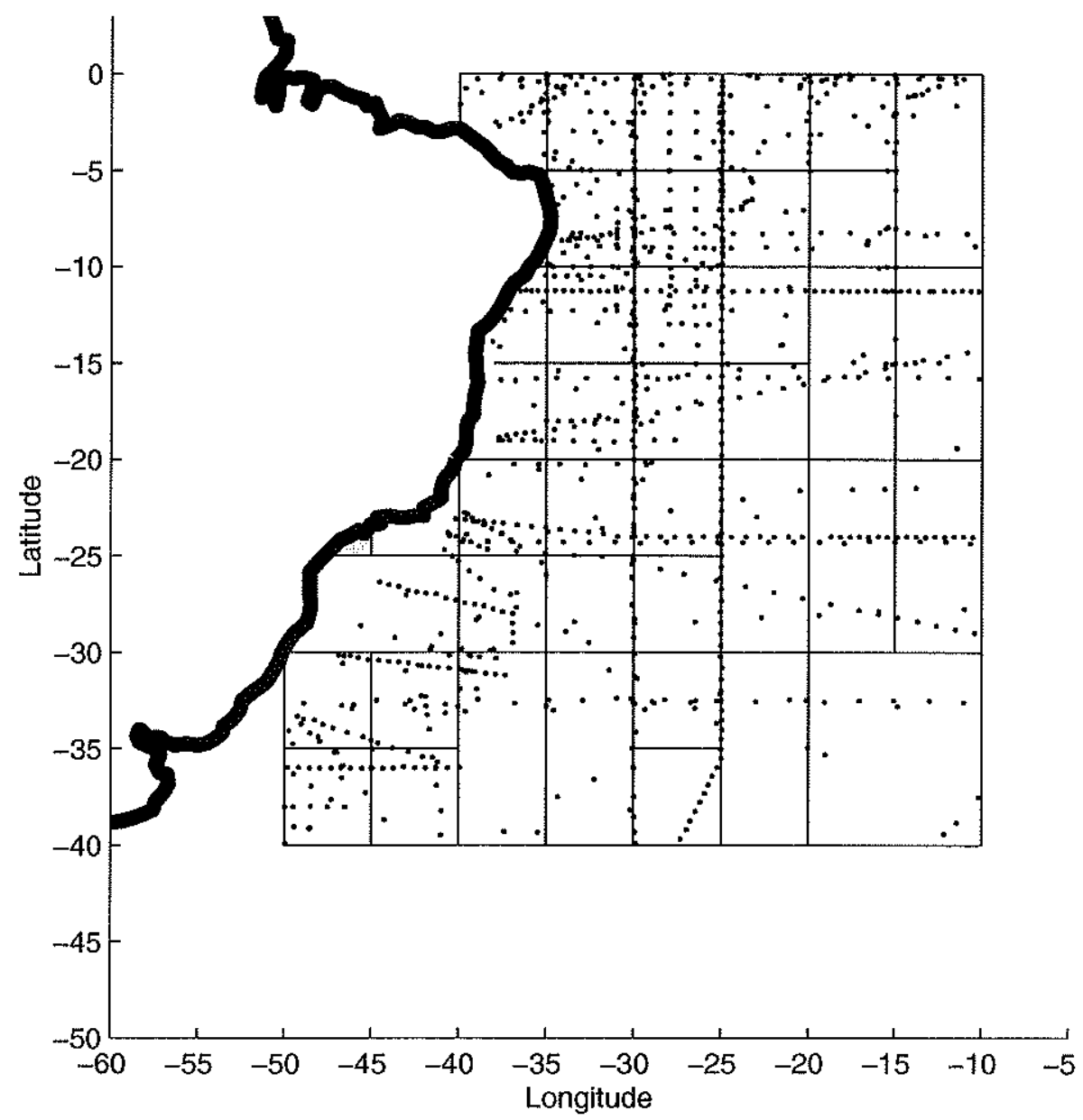

Figure 3.1: HydroBase contains 1040 stations in the Brazil Basin which have data extending as deep as $1000 \mathrm{db}$. These data were binned into boxes, as shown, for analysis. The points are spatially and temporally diffuse. 


\subsubsection{WOCE section data}

Because WOCE hydrographic data was collected using a CTD, it is much better resolved in the vertical, with data typically every $2 d b$. They are also better resolved in the horizontal, although with stations about every $50 \mathrm{~km}$, we do not expect to resolve eddies, but we may be able to find pairs of adjacent eddies as seen in the case of the eddy associated with float 188. Data located between 57.5 and $7.5^{\circ}$ West, and 47.5 and $2.5^{\circ}$ South were used. Figure 3.2 shows the geographical distribution of the stations, and the boxes used for analysis. Although the number of stations, 899 , is comparable to the HydroBase study, the spatial distribution of the stations looks very different. Ship tracks are clearly discernible. (The data used is available through the WOCE Hydrographic Program office at Scripps Institute of Oceanography.)

\subsection{Eddy Identification Criteria}

Because of striking differences between the HydroBase and WOCE hydrographic datasets, we not only combined all the data for analysis, we also ran separate analyses for the two groups. Only the separate analyses will be discussed here, because the results were different for the two cases, and the results from the combined study offer no additional insight.

While the hydrographic data discussed in the previous chapter suggests anomalous signals in temperature, salinity and stratification, we chose to generalize our search to find eddies without salinity and temperature anomalies. Because the anomaly in stratification is dynamically necessary for a baroclinic eddy, we elected to search for stations which recorded especially thick or thin density layers, and to then determine whether or not those same 


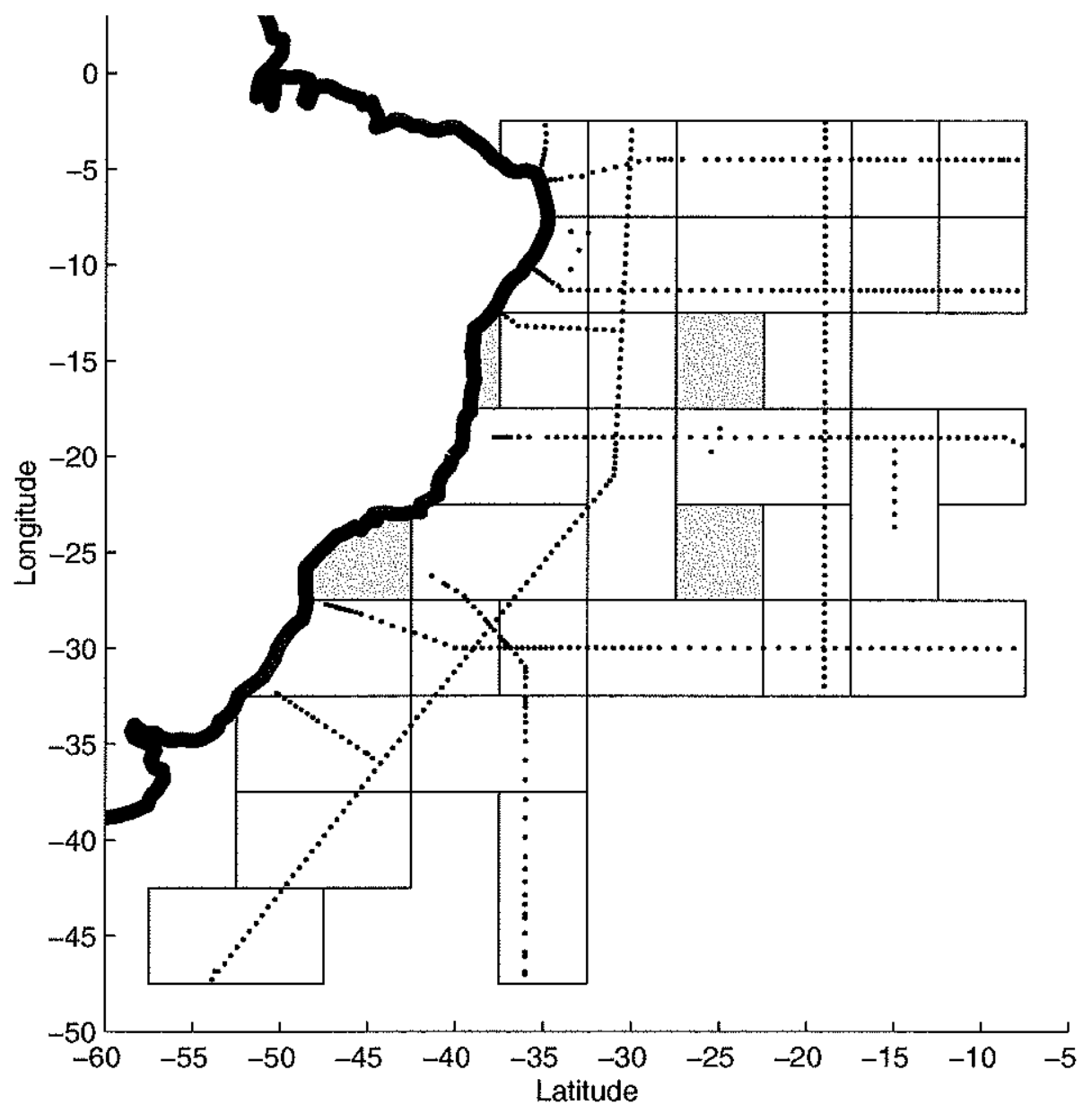

Figure 3.2: WOCE section data in the Brazil Basin contains 899 stations which were binned into the boxes shown. The stations were all obtained through a few temporally close cruises, whose tracks are clearly discernible. 
stations also exhibit temperature or salinity anomalies. Because we were looking for deep eddies similar to the ones tracked by the floats, and because we felt that shallower waters are likely to exhibit a great deal of temporal and spatial variation which could be misinterpreted, we only looked for eddies at depths greater than $1000 \mathrm{db}$.

The stations were divided into geographic boxes (as shown in figures 3.1 and 3.2) for the purpose of determining local characteristics. We used $5^{\circ}$ square boxes when doing so provided 10 or more stations for comparison, and in one case in which a coastal box contains 6 stations that are closely clustered, and otherwise we combined adjacent boxes with an eye for assigning physically proximate stations to the same box.

To search for eddies, we searched for stations where the vertical distance between isopycnal surfaces was anomalous compared to other stations within the same box. For each station, the difference in pressure between, for instance, the $\sigma_{2}=36.5$ and $\sigma_{2}=36.575$ surfaces was calculated using linear interpolation between data points in the vertical. Once this had been done for every station within a certain box, the mean and standard deviation of these thicknesses was determined. (By thickness, we mean the difference in pressure, not in depth, between isopycnal surfaces). Any station for which this thickness was at least 3 standard deviations greater than or less than the box mean was flagged as an eddy. The process was repeated for all the boxes. Then the same thing was done for the next density layer, and so on until the entire water column had been examined. Density layers overlapped each other in the vertical by half in the first run, then by two-thirds, and so on until increasing the overlap ceased to produce identification of any new eddies. All layers corresponded to a density difference of $\sigma_{2}=0.075$.

The limit of 3 standard deviations was chosen, somewhat arbitrarily, because the eddy 
associated with float 188 exhibits density layers more than 3 standard deviations thicker than its surroundings at several levels. We recognize that our identification criterion is less than perfect, and, due to variations of background stratification within boxes, as well as poor resolution in the vertical, some stations were incorrectly identified as eddies, while some eddies went undetected. However, we were reluctant to add a temperature or salinity signature to the identification criteria because we wanted to avoid a situation wherein our results are simply a reflection of our expectations.

In the previous chapter, Figure 2.8 shows two eddies: one a concave eddy with an interior stratification maximum sandwiched vertically between two regions of anomalously low stratification, the other a stratification minimum surrounded by two stratification maxima. This makes it clear that eddies which are identifiable as belonging in one category or the other may meet the criteria for having both anomalously thin and thick density layers. When an eddy was identified as meeting both criterion, the station was first examined visually in the context of nearby data acquired on the same cruise, and eliminated from one of the categories only if its characterization as one category of eddy was obvious. In many cases, especially when surrounding data was unavailable, this proved impossible. For remaining stations which were doubly identified, and which had the vertical resolution necessary (WOCE stations), we smoothed the density profile using simple averaging over layers $50 \mathrm{db}$ thick, took the vertical derivative, and looked for a pattern where a PV anomaly of one sign was sandwiched vertically between anomalies of the opposite sign. This allowed us to eliminate some stations from one of the two categories. We recognize that this procedure induces a slight bias toward equipartition.

The identified eddies were then compared to surrounding stations to determine whether 
or not they exhibit anomalous temperature or salinity signals. Because of the overlapping density layers used, most eddies were identified at several (usually consecutive) density levels. Of those, the middle level (or the level just above the middle, if the eddy was identified at an even number of levels) was used. The salinity and potential temperature were determined both for the eddy at that depth, and for all the other stations within the same box and at the same depth. This was done using linear interpolation in the vertical. We were then able to determine how many standard deviations warmer or colder, and saltier or fresher an eddy was compared to the local mean.

\subsection{Results}

The results are presented here in two sections, corresponding to the two datasets used.

\subsubsection{HydroBase Results}

The locations of eddies identified in HydroBase data are shown in figure 3.3. A total of 31 convex eddies and 21 concave eddies were found. Included in both totals are 5 instances of eddies identified as both convex and concave. In all, $4.5 \%$ of stations were taken in a lens, $3.0 \%$ were in a convex lens, and $2.0 \%$ were in a concave lens. Because the lower limit of deviation in thickness, 3 standard deviations, was somewhat arbitrary, it is comforting to see that the percent of stations taken in eddies (4.5\%) is comparable to the percent of float days spent in eddies (7.6\%). We would not expect to see identical numbers, though, both because stations with deviant properties were eliminated from the database, and because the depth ranges studied were different. 


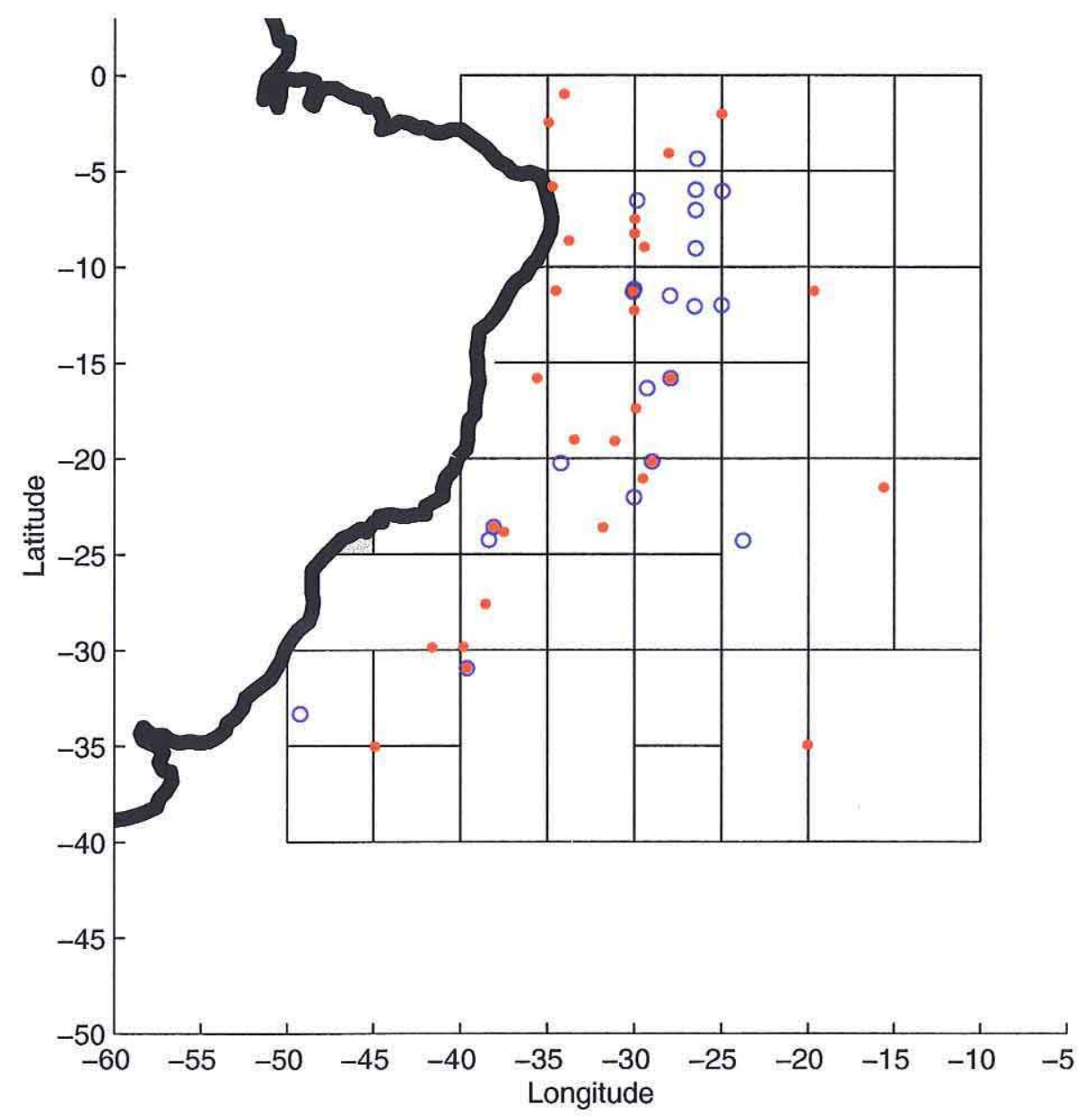

Figure 3.3: Thirty-one convex eddies (shown in red), and 21 concave eddies (shown in blue) were identified in HydroBase data, including 5 stations identified as both. 
No pairs of horizontally adjacent eddies were identified. Recall, though, that the horizontal resolution is low in this dataset, and the stations were taken over a long period of time.

The mean and standard deviation of depths were, for convex lenses, $1630 d b \pm 430$ $d b$, and for concave lenses, $1800 d b \pm 700 d b$. Apparently, we see eddies shallower than the floats tracked, which may explain

but these data are poorly resolved in the vertical, and resolution decreases with depth. Many stations extend not to the bottom but only to some intermediate depth, while others extend to the bottom but with more diffuse sampling in the abyss. Perhaps deeper eddies went undetected, or eddies whose stratification signal extends over a large vertical range were identified in the shallower regions.

Figure 3.4 shows the temperature and salinity deviations exhibited by the eddies compared to the box mean. It appears that both types of eddies are both warmer and saltier than surrounding waters. This suggests formation in the north or northwest, where, as figures 3.5 and 3.6 show, ambient temperatures and salinities are greater. Warm, salty equatorial waters are advected southward by a deep western boundary current.

\subsubsection{WOCE Results}

The geographic locations of eddies identified in WOCE section data are shown in figure 3.7. In total, 13 convex eddies and 19 concave eddies were found, including 2 stations identified as both convex and concave. Generally, $3.3 \%$ of stations were identified as eddies, $1.4 \%$ as

convex and $2.1 \%$ as concave. While these populations are still comparable to the percent of 

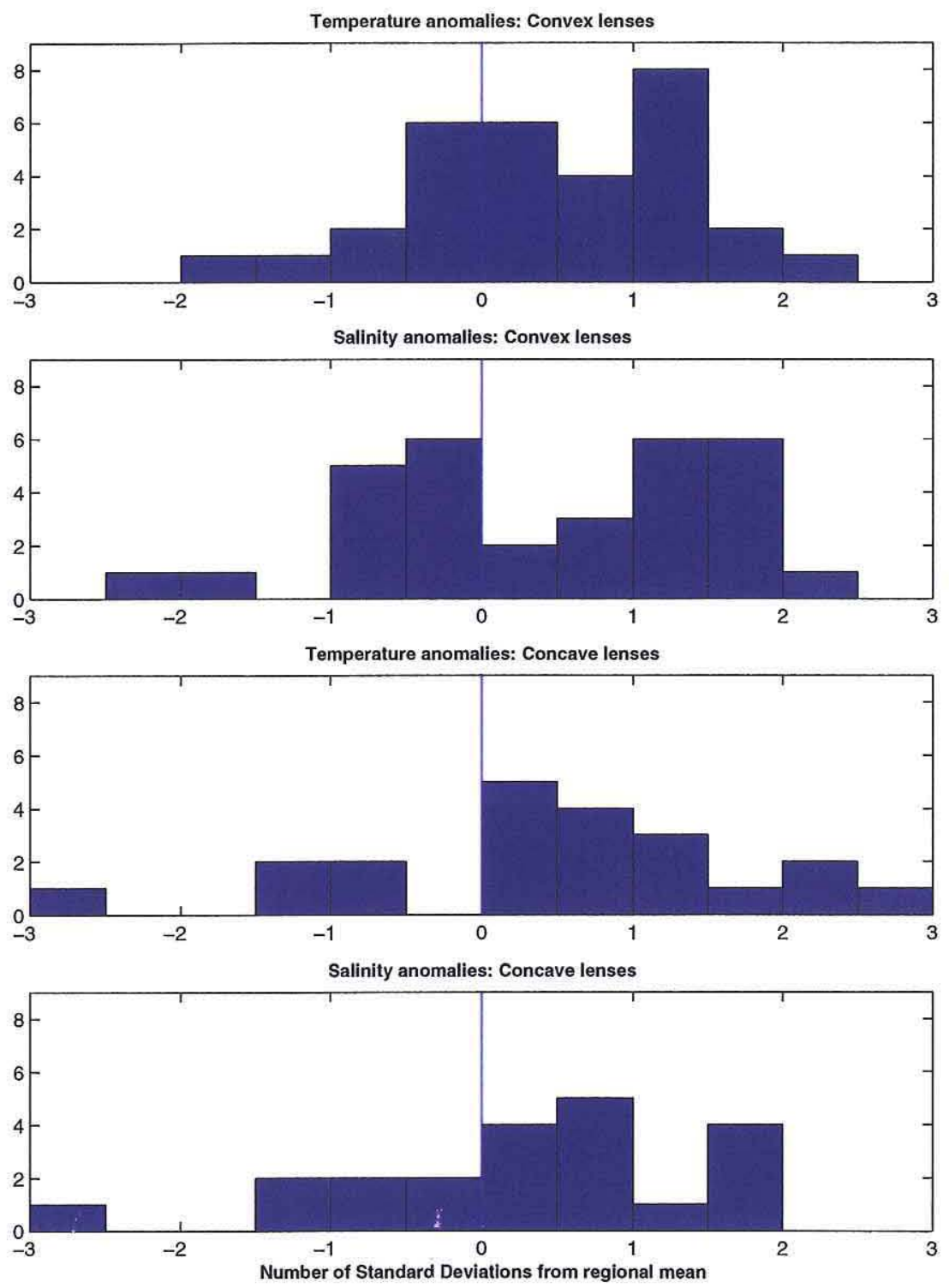

Figure 3.4: For each eddy identified in HydroBase data, the mean and standard deviation of both temperature and salinity were determined from all HydroBase data at eddy-depth in the local box (by linearly interpolating in the vertical). We then determined how many standard deviations warmer and saltier the eddy was than the local average. Here, we see a clear tendency for both types of eddies to be warmer and saltier than surrounding water. 


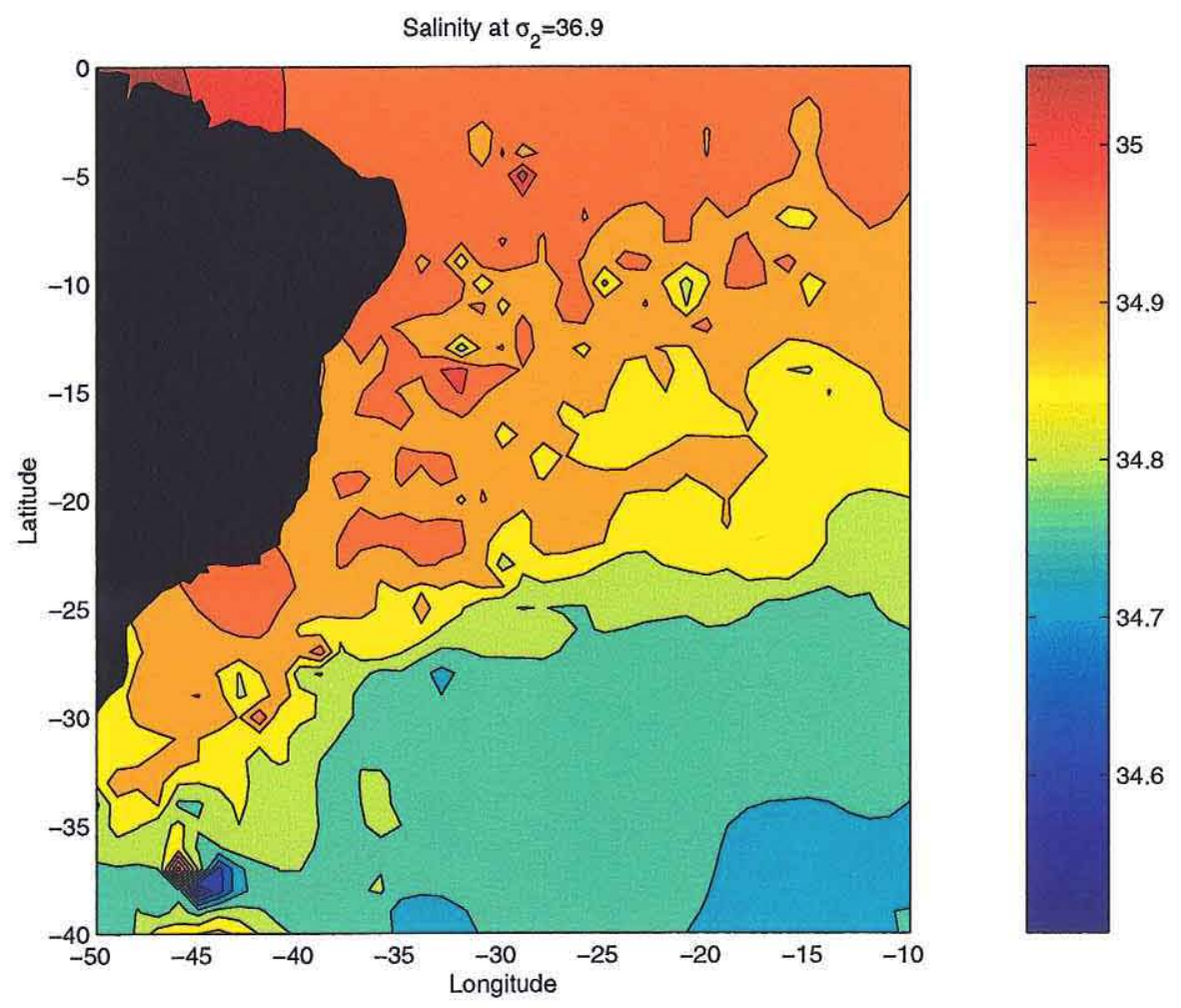

Figure 3.5: This map of salinity at the $\sigma_{2}=36.9$ density level was made using all available hydrographic data. The salinity was determined at each station by linear interpolation in the vertical. It was then mapped to a $1^{\circ} \mathrm{C}$ by $1^{\circ} \mathrm{C}$ grid. 


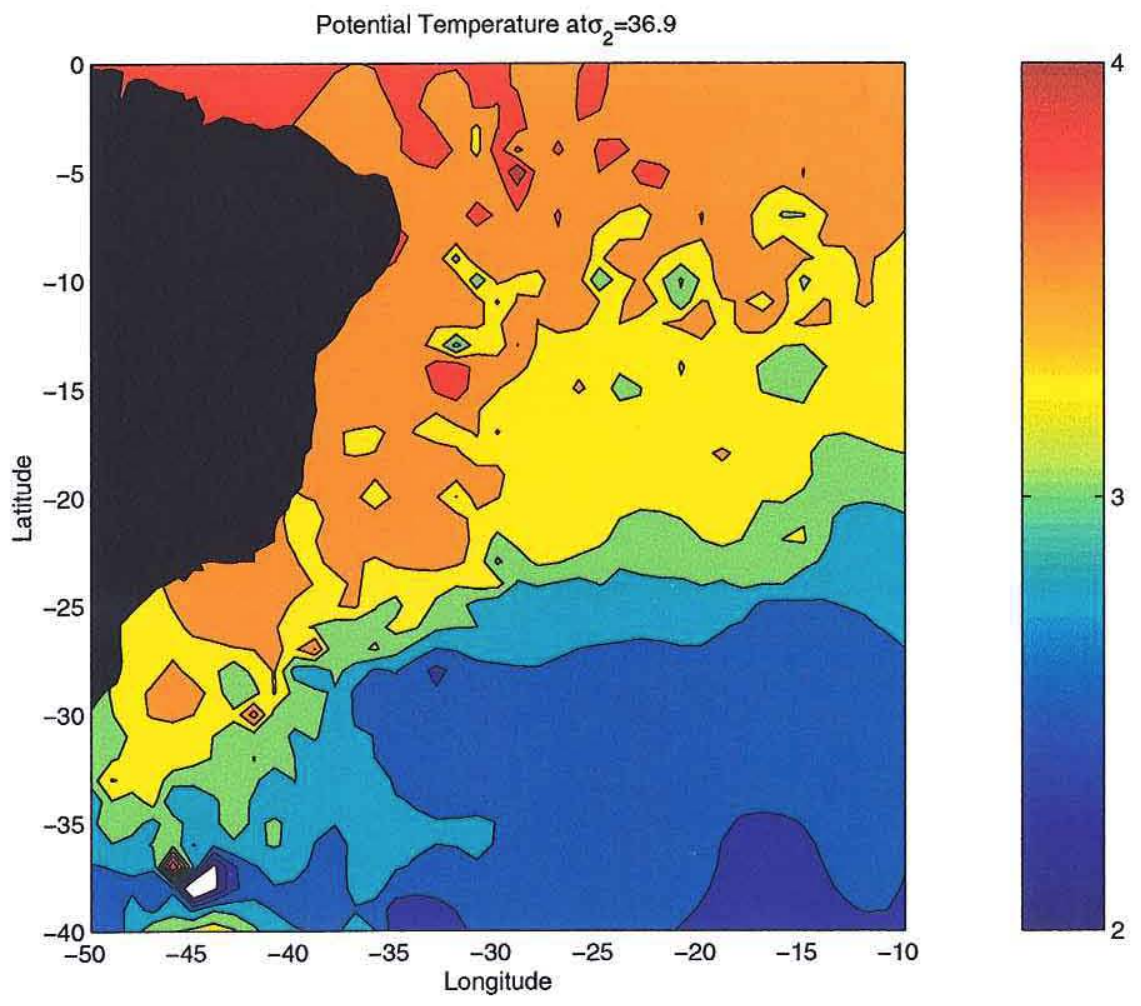

Figure 3.6: This map of temperature at the $\sigma_{2}=36.9$ density level was made using all available hydrographic data. The temperature was determined at each station by linear interpolation in the vertical. It was then mapped to a $1^{\circ} \mathrm{C}$ by $1^{\circ} \mathrm{C}$ grid. 


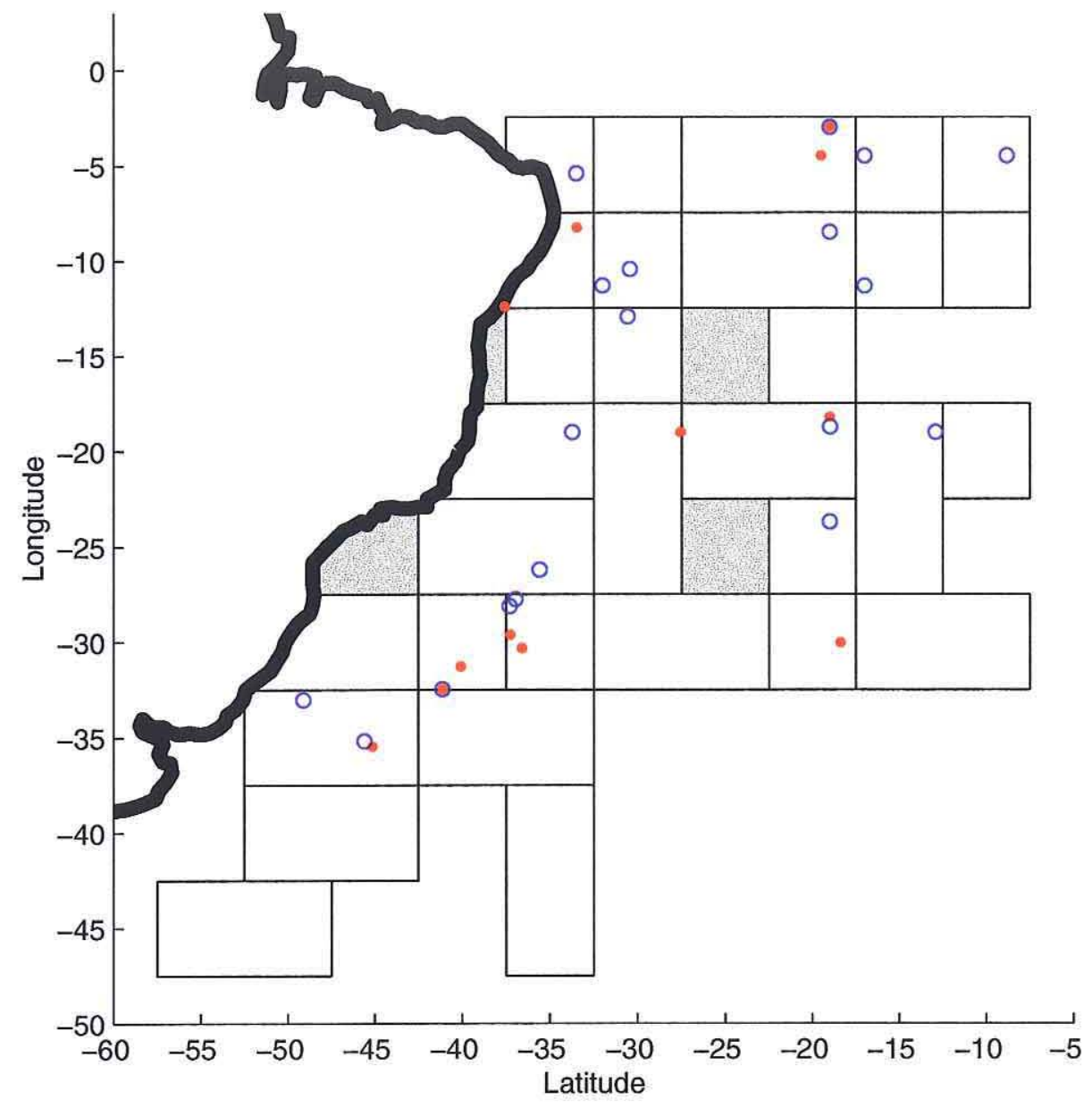

Figure 3.7: Thirteen convex eddies (shown in red), and 19 concave eddies (shown in blue) were identified in WOCE section data, including 2 stations identified as both.

float days spent looping, we were surprised to find them slightly lower than the HydroBase results, because no anomalous observations were eliminated from this database.

When compared to surrounding WOCE hydrographic data, these eddies were not found to be anomalous in temperature or salinity in any systematic way. Histograms of the salinity and temperature anomalies are shown in figure 3.8. Eddies are apparently likely to be different from the local mean, but the sign of the anomaly is random. There is also no dependence on depth.

Hydrographic data and $\theta$-S diagrams of a few identified eddies are shown in figure 3.9. 


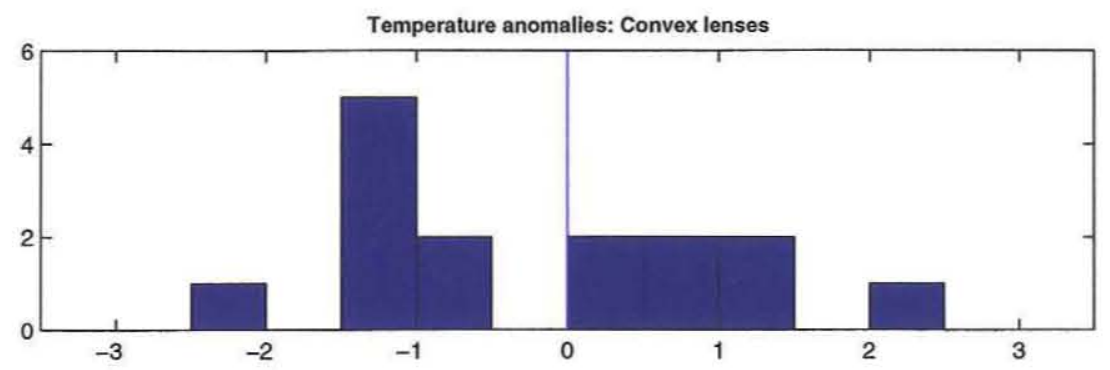

Salinity anomalies: Convex lenses

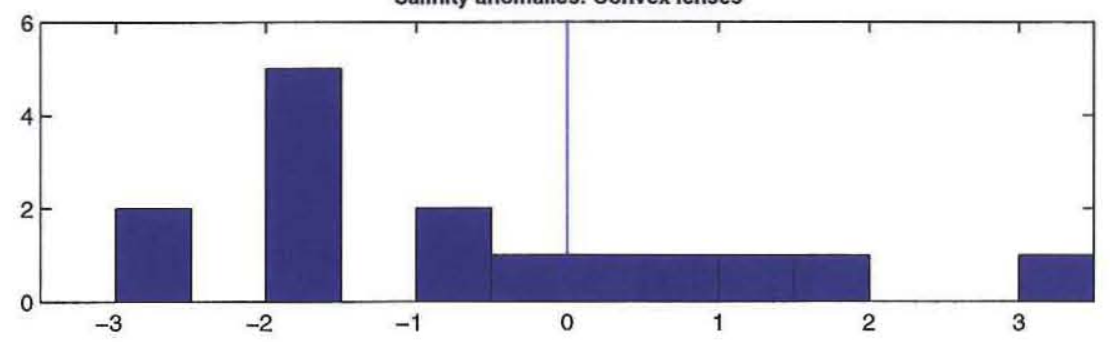

Temperature anomalies: Concave lenses

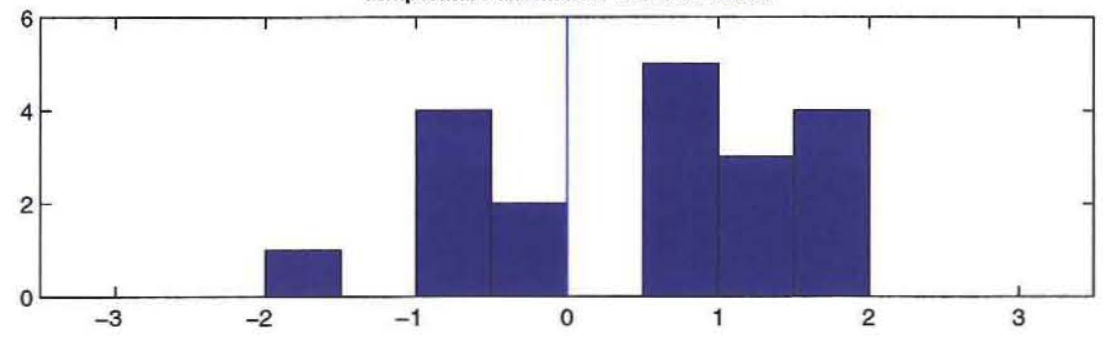

Salinity anomalies: Concave lenses

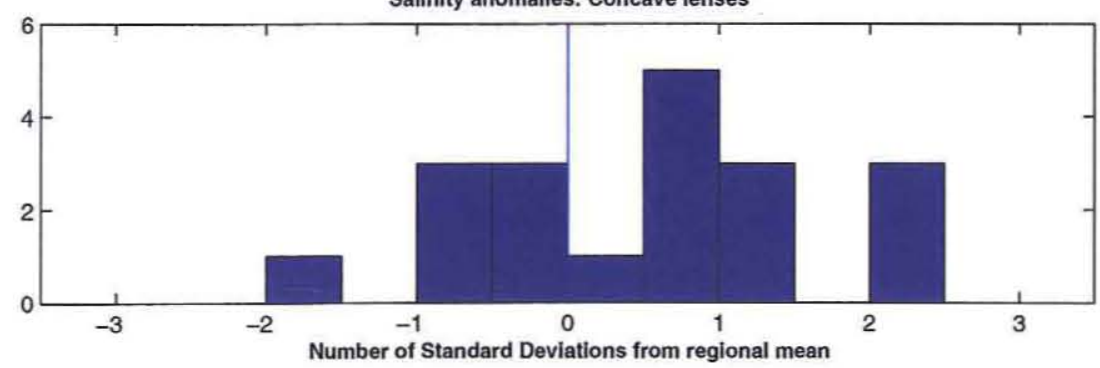

Figure 3.8: For each eddy identified in WOCE section data, the mean and standard deviation of both temperature and salinity were determined from all WOCE section data at eddy-depth in the local box (by linearly interpolating in the vertical). We then determined how many standard deviations warmer and saltier the eddy was than the local average. Apparently, the identified eddies do not differ from the surrounding waters in any systematic way. 
One concave lens, one convex lens, and two concave-convex pairs are shown. In three of the four cases, there is no clear deviation from local mean $\theta$-S characteristics.

Two pairs of horizontally adjacent eddies of opposite rotational sense were found. One is the eddy pair discussed above, and shown in figure 2.8 and figure 3.9. Again, we see that both lenses are warmer and saltier water than the local environment. The second pair is also shown in figure 3.9. Here the primary eddy is clearly the deep $(3300 \mathrm{db})$ convex lens, but the algorithm used also identified a shallower $(1500 \mathrm{db})$ concave lens next to it, which could either be a genuine, but small, pinch in isopycnals, or a misidentification by the algorithm. If it is a genuine stratification maximum, it may represent a tilting of the top of the eddy, with the stratification maximum which we would expect to find directly above the eddy instead horizontally displaced, or it could be a secondary eddy. Either way, one would expect it to have a role in advecting the primary eddy. However, these eddies do not show temperature or salinity anomalies, suggesting either that they were formed locally or that they moved from another location where ambient temperature and salinity are similar to the location where they are observed.

Figure 3.10 shows the distribution of cyclonic and anticyclonic eddies with depth, as determined from each of the three datasets used (WOCE, HydroBase, and float data). The floats were partitioned into two groups, and each group was programmed to remain at a certain pressure level. Accordingly, both the cyclonic and anticyclonic depth distributions show a bimodal tendency. However, it is also clear, and was discussed in chapter two, that the deeper floats were more likely to exhibit cyclonic looping, and the shallower floats were more likely to exhibit anticyclonic looping. We see the same trend evident in WOCE hydrographic data, and, to a lesser extent, in HydroBase data. Generally, shallower eddies were identified 

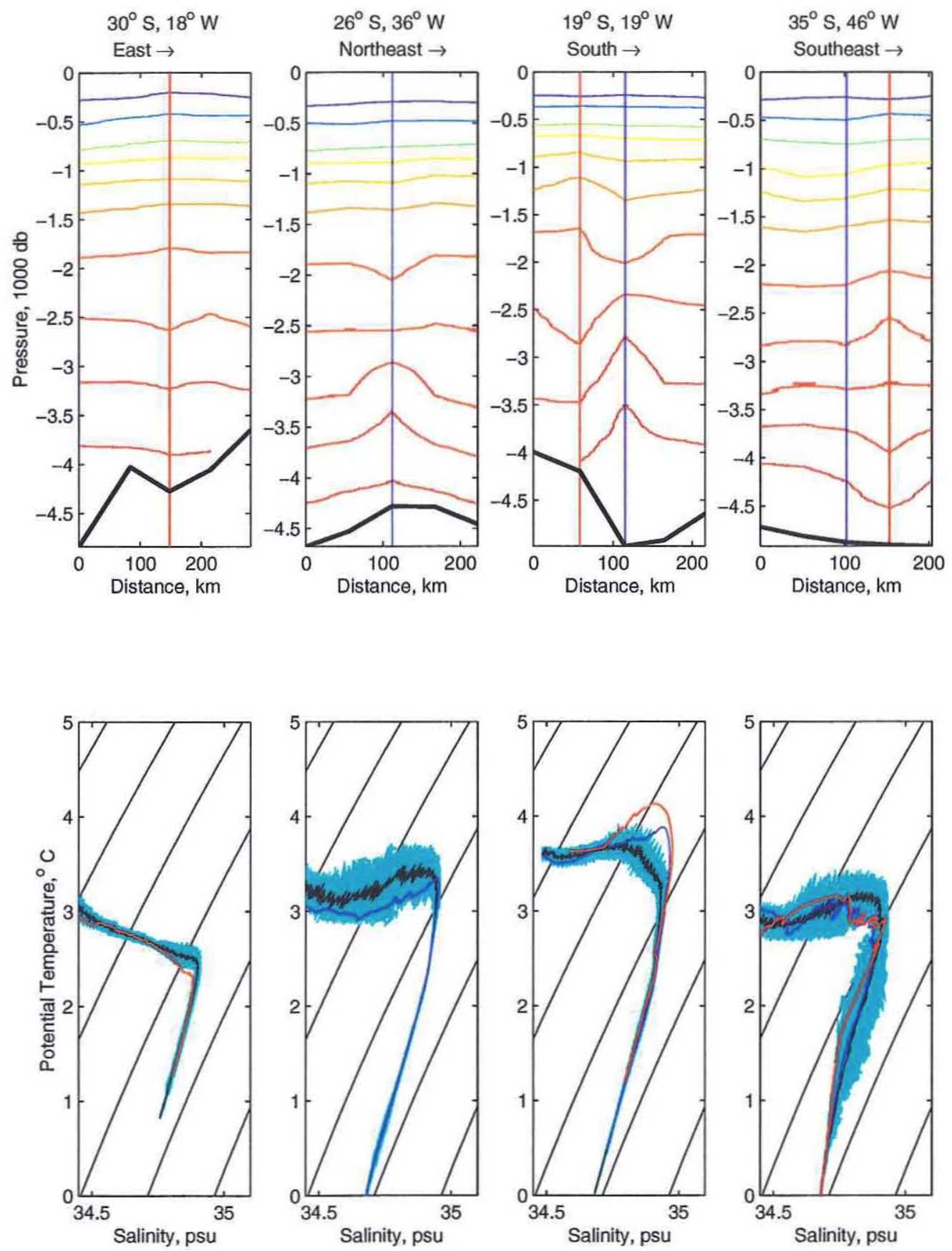

Figure 3.9: A few examples of identified eddies are shown. Hydrographic data and $\theta-\mathrm{S}$ diagrams for one concave lens, one convex lens, and two concave-convex pairs are shown. $\theta$-S diagrams of eddies, in blue and red, are superimposed over the local mean (in black) and one standard deviation (in cyan). These were calculated as the box-wide mean and standard deviation of temperature and salinity in density bins $0.001 \mathrm{~kg} / \mathrm{m}^{3}$ thick throughout the water column below $1000 \mathrm{db}$ depth. 

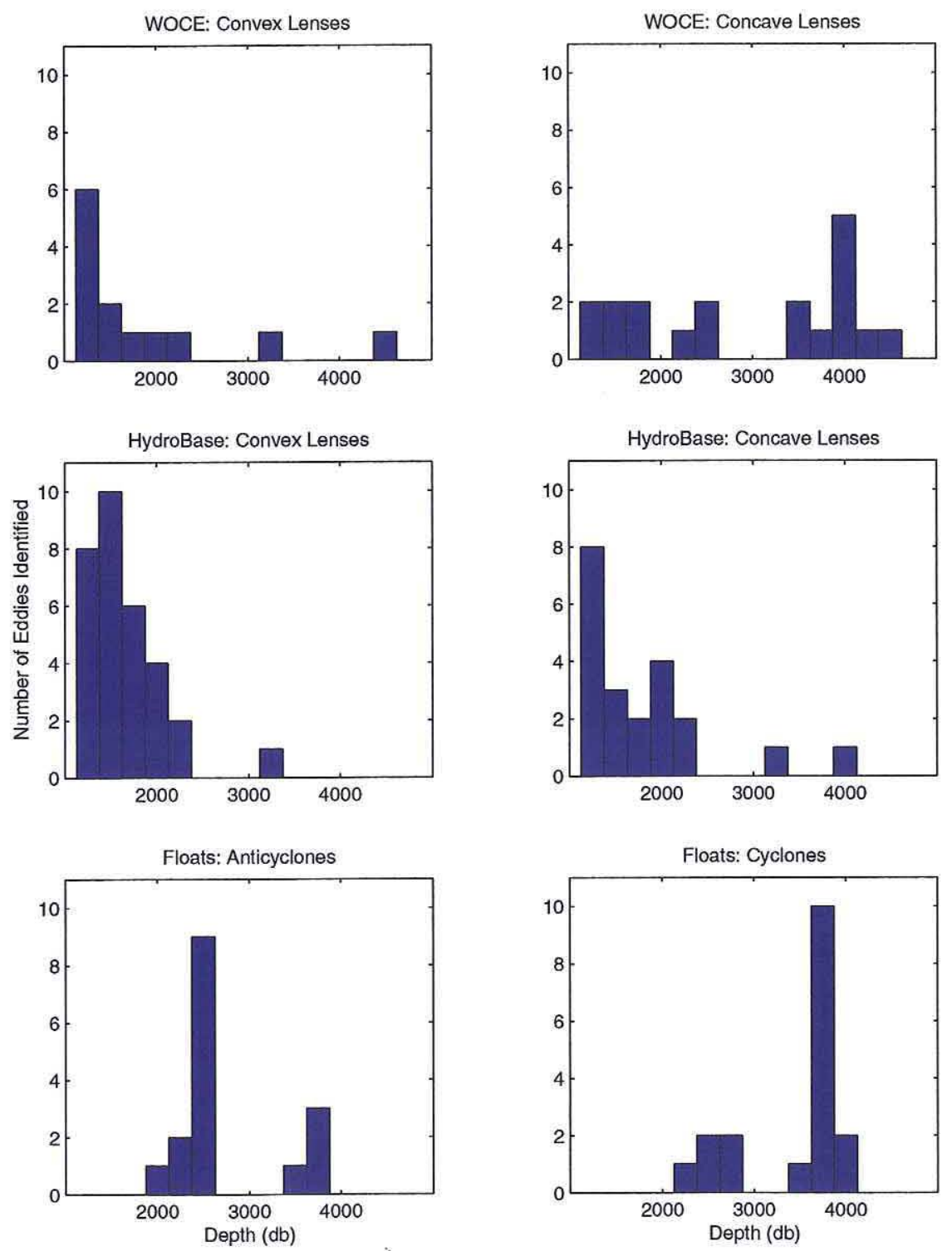

Figure 3.10: The distribution of cyclonic and anticyclonic eddies with depth, as determined from each of the three datasets used (WOCE, HydroBase, and float data), shows a tendency for cyclones (concave lenses) to be found deeper in the water column than anticyclones (convex lenses). 
in HydroBase data. This is probably because eddies were more likely identified higher in the water column, where vertical resolution of the and the vertical gradients were much larger than instrumental errors.

\subsection{Conclusions}

A search through available hydrographic data for stations where the distance between density layers is especially thick or thin, compared to local background stratification, revealed several eddies. Of WOCE section data, $3.3 \%$ of stations were determined to have been taken in an eddy, and of HydroBase data, $4.5 \%$. These numbers compare to the percent of float days which were spent looping: $7.6 \%$. In HydroBase data, 31 convex and 21 concave eddies were found. In WOCE section data, 13 convex and 19 concave eddies were found.

The results from the HydroBase study indicate that both types of eddies are likely to be enriched in warmer, saltier water than is locally typical (see figure 3.4), which suggests formation in the north or northwest region of the basin. This was our expectation upon beginning the hydrographic studies, both because of the observed float temperature records, some of which suggest higher temperatures while looping, and because of the hydrographic data (obtained through WOCE) of the eddy tracked by float 188. However, the systematic examination of WOCE hydrographic data did not produce such consistent results. While water which composes an eddy is likely to have characteristics which differ from local waters (see figure 3.8), the anomaly is not dominantly of one sign.

Although HydroBase data is better resolved at shallower levels than it is in the abyss, and therefore more eddies were found in shallower regions in that study, both the HydroBase 
and the WOCE studies generally identified concave lenses deeper than convex ones. This result is consistent with float data, which indicates that eddies below $3000 d b$ depth are dominantly cyclonic, while those shallower are primarily anticyclones.

The worldwide bias toward anticyclonic SCVs that McWilliams (1985) notes was not confirmed by these studies. Perhaps the Brazil Basin is fundamentally different. Perhaps dominant formation and destruction mechanisms are different here from other basins, allowing for equal populations of cyclones and anticyclones. There is, however, another interesting and profound possibility. Note that we were lucky in this study to have found both types. If floats had been programmed only for the shallower $(2500 \mathrm{db})$ range, we would have found primarily anticyclones, and then we would have likely searched through hydrographic records for these shallow, convex features. We would have identified some. Further investigations of these features would have been concentrated at this depth, and we would have almost certainly found the features we sought. A similar scenario seems to have taken place with regards to meddies: they were initially identified in a certain geographic area, which was then further explored, each study looking for anticyclones, and each study confirming, more certainly than the last, that all meddies are indeed anticyclones. It was only when a different region, to the north, was explored that cyclonic SCVs were identified (Schauer, 1989, and Colin de Verdiere et al. , 1989). 


\section{References}

Beckmann, A. and R. Kase: 1989, 'Numerical Simulation of the Movement of a Mediterranean Water Lens', Geophys Res Lett 16 (1), 65-68.

Colin de Verdiere, A., H. Mercier and M. Arhan: 1989, 'Mesoscale Variability Transition from the Western to the Eastern Atlantic along 48 N', J Phys Ocean 19, 1149-1170.

Colin de Verdiere, A.: 1992, 'On the Southward Motion of Mediterranean Salt Lenses', $J$ Phys Ocean 22, 413-420.

Curry, R.G.: 1996, 'HydroBase; A Database of Hydrographic Stations and Tools for Climatological Analysis', WHOI publication number WHOI-96-01, 44 pages.

Cushman-Roisin, B.: 1994, Introduction to Geophysical Fluid Dynamics, Prentice Hall, NJ, 320 Pages.

DeMadron, X.D., and G. Weatherly: 1994, 'Circulation, transport and bottom boundary layers of the deep currents in the Brazil Basin', J Mar Sci 52, 583-638.

Flierl, G. R., V. D. Larichev, J. C. McWilliams and G. M. Reznik: 1980, 'The dynamics of baroclinic and barotropic solitary eddies', Dyn Atm Oceans 5, 1-41.

Garrett, C.: 1989, 'Are diapycnal fluxes linked to lateral stirring rates?', 'Aha Huliko'a Hawaiian Workshop, 5th, Univ. of Hawaii, Jan. 17-20, 1989, Parameterization of Smallscale Processes: Proceedings, Honolulu, Hawaii Institute of Geophysics p. 317-327.

Hogg, N. G. , Owens, W. B., Siedler, G., and Zenk, W.: 1996, 'Circulation in the Deep Brazil Basin', from Wefer, G., Berger, W. H., Siedler, G., and Webb, D. J., (eds), 1996, 'The South Atlantic: Past and Present Circulation.' Springer-Verlag, Berlin Heidelberg, 249-260.

Hogg, N. and W. B. Owens: 1999, 'Direct measurements of the deep circulation within the 
Brazil Basin', Deep Sea Res II 46 (1-2), 335-353.

Hogg, N. and H. M. Stommel: 1985, 'The heton, an elementary interaction between discrete baroclinic geostrophic vortices, and its implication concerning eddy heat-flow', Proc Roy Soc London A397, 1-20.

Hogg, N. and H. M. Stommel: 1990, 'How currents in the upper thermocline could advect meddies deeper down', Deep Sea Res 37(4A), 613-623.

Huppert, H. E. and K. Bryan: 1976, 'Topographically generated eddies', Deep Sea Res 23(8), $1465-1476$.

McDonald, N.R., and D.N. Straub: 1995, 'Meridional Motion of Mixing Eddies', J Phys Ocean 25, 726-634.

McWilliams, J.C.: 1985, 'Submesoscale Coherent Vortices in the Ocean', Rev Geophys 23 (2), 165-182.

Meacham, S.P., K.K. Pandratov, A.F. Shchepetkin and V.V. Zhmur: 1994, 'The interaction of ellipsoidal vortices with background shear flows in a stratified fluid', Dyn Atm Oceans 21, 167-212.

Paillet, J., M. Arhan and M.S. McCartney: 1998, 'Spreading of Labrador Sea Water in the eastern North Atlantic', J Geophys Res 103 (C5), 10223-10239.

Richardson, P.L., D. Walsh, L. Armi, M. Schroder and J.F. Price: 1989, 'Tracking Three Meddies with SOFAR Floats', $J$ Phys Ocean 19, 371-383.

Riser, S.C., Owens, W.B., Rossby, H.T., and Ebbesmeyer, C.C.: 1986, 'The Structure, Dynamics and Origin of Small-Scale Lens of Water in the Western North Atlantic Thermocline', $J$ Phys Ocean 16, 572-590.

Rossby, T., D. Dorson and J. Fontaine: 1986, 'The RAFOS System', J Atm Ocean Tech $3(4), 672-679$.

Schauer, U.: 1989, 'A deep saline cyclonic eddy in the West European Basin', Deep Sea Res 36 (10), 1549-1565.

Shapiro, G. I., E.D. Barton and S. L. Meschanov: 1997, 'Capture and release of Lagrangian floats by eddies in shear flow', $J$ Geophys Res 102, 27887-27902. 